\author{
UNIVERSITY OF CALIFORNIA \\ COLLEGE OF AGRICULTURE \\ AGRICULTURAL EXPERIMENT STATION \\ BERKELEY, CALIFORNIA
}

\title{
THE PRINCIPLES AND PRACTICE OF SUN-DRYING FRUIT
}

BY

A. W. CHRISTIE AND L. C. BARNARD

BULLETIN No. 388

MAY, 1925 
Digitized by the Internet Archive in 2012 with funding from University of California, Davis Libraries 


\title{
THE PRINCIPLES AND PKACTICE OF SUN-DRYING FRUIT
}

\author{
By A. W. CHRISTIE AND L. C. BARNARD
}

\section{EXTENT OF THE DRIED FRUIT INDUSTRY}

From the beginning of fruit growing in California, sun-drying has been one of the principal methods of preserving fruit for marketing. While sometimes used as a means of preserving fruit which could not be marketed through other channels such as fresh sale or canning, sun-drying is a primary industry, as evidenced by the large proportion of fruits grown expressly for drying. The quality and world-wide distribution of her dried fruits have made California the leader of the world in this field. In fact, the dried fruits of California are considered the standard of excellence.

Various causes have contributed to the development of sun-drying in California, the most important being its sub-tropical climate. The long, warm, dry summer is not only favorable to the production of the principal drying fruits, but since the ripening of most of these fruits normally occurs in dry weather, it is possible to utilize this simple, natural method of food preservation. Because California is situated several thousands miles from her principal markets, dried fruits represent the most economical form in which the crops can be transported and offered for sale. Although coöperative canneries are growing, drying is in general the principal method by which the individual grower can preserve his crop in a durable form. The great increase in the production of dried fruits in recent years has been largely due to the activities of the several coöperative marketing associations. These associations have enabled the growers to retain control of their dried products through all the stages of packing and distribution to the ultimate consumer and by means of standardization, attractive packaging and advertisement to very greatly increase the demand for California dried fruits.

According to the 1919 census, California produced 94 per cent of all the dried fruits of the United States. With the exception of prunes in the Pacific Northwest and evaporated apples in several states, Cali- 
fornia enjoys a practical monopoly in the production of nearly all kinds of dried fruits. The extent of the industry can be seen by reference to Table 1, which gives the tonnage produced in 1923 with a conservative estimate of their value to the producer. Table 2, gives the total acreages of certain fruits for 1924. It is difficult to estimate what proportion of these acreages were devoted to the production of dried fruits. In most cases, the proportion of the total crop which is dried varies considerably from year to year according to changes in the market for fresh and canned fruits. From 30 to 40 per cent of the peach and apricot crops are dried normally and of pears usually not over 10 per cent. Over 90 per cent of the figs and raisin grapes are dried and the quantity of prunes not dried is negligible.

\section{TABLE 1}

Tonnage and Value of Sun-Dried Fruits for 1923

\begin{tabular}{|c|c|c|c|}
\hline & \multirow{2}{*}{ Dry tons* } & \multicolumn{2}{|c|}{ Estimated farm value } \\
\hline & & Per pound & Total \\
\hline Apricots....... & 30,000 & $20 \mathrm{c}$ & $\$ 12,000,000$ \\
\hline Figs..... & 9,500 & $7 \mathrm{c}$ & $1,330,000$ \\
\hline Peaches.... & 26,000 & $10 \mathrm{c}$ & $5,200,000$ \\
\hline Pears........... & 2,000 & $10 \mathrm{c}$ & 400,000 \\
\hline Prunes... & 131,000 & $7 \mathrm{c}$ & $18,340,000$ \\
\hline 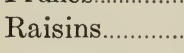 & 280,000 & $4 \mathrm{c}$ & $22,400,000$ \\
\hline Total.... & 478,500 & & $\$ 59,670,000$ \\
\hline
\end{tabular}

* Compiled by Dried Fruit Association of California.

TABLE 2

Acreages of Certain Fruits in 1924*

\begin{tabular}{|c|c|c|c|}
\hline & Bearing & Non-bearing & Total \\
\hline Apricots... & 68,887 & 21,022 & 89,909 \\
\hline Figs..................................... & 23,982 & 24,269 & 48,251 \\
\hline Peaches... & 120,947 & 28,455 & 149,402 \\
\hline Pears........................... & 45,407 & 24,593 & 71,000 \\
\hline 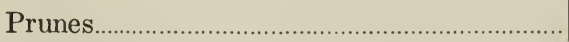 & 138,558 & 47,261 & 185,819 \\
\hline 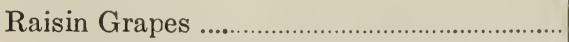 & 297,164 & 60,291 & 357,455 \\
\hline
\end{tabular}
1924

Compiled by E. E. Kaufman, Calif. Coop. Crop Reporting Service. Includes acreages planted in 
From the large-non-bearing acreages given in Table 2, to which should be added extensive plantings made in 1925, it is evident that the production of dried fruits must inevitably increase. If fresh shipment and canning do not keep pace with the increasing production, it may become necessary to dry a greater proportion of the fruit crop than formerly. The production of dried fruits is also expanding in other parts of the world, notably Australia and South Africa. At present, the rate of financial exchange and other conditions resulting from the world war seriously restrict exports of dried fruits from the United States and moreover permit the importation of certain dried fruits from the Mediterranean countries. The amount of dried fruit exports and imports in 1923 can be seen from Table 3.

\section{TABLE 3}

United States Imports and Fxports of Sun-Dried Fruits

(Ficcal Year 1922-23)

\begin{tabular}{|c|c|c|}
\hline & Tons imported & Tons exported \\
\hline Apricots... & \multirow{6}{*}{$\begin{array}{r}0 \\
18,293 \\
0 \\
0 \\
6,168 \\
9,462\end{array}$} & \multirow{6}{*}{$\begin{array}{r}5,597 \\
0 \\
2,793 \\
39,615 \\
46,981 \\
0\end{array}$} \\
\hline Figs ................. & & \\
\hline Peaches.. & & \\
\hline Prunes... & & \\
\hline Raisins.. & & \\
\hline Currants....... & & \\
\hline Total.. & 33,923 & 94,986 \\
\hline
\end{tabular}

* From U. S. D. A. Year Book, 1923.

\section{PRINCIPAL LOCALITIES AND VARIETIES FOR SUN-DRYING}

With the exception of the extreme northern part of the state and the mountainous districts of the Coast Range and the Sierra Nevada, fruits are grown and dried in almost every agricultural region of California. Some districts have been found to be particularly suited to the growing of certain kinds of fruit and have consequently taken the lead in the production of these fruits. Likewise certain varieties because of higher quality or yield have been most extensively planted and dried and have, therefore, become the trade standard. The following paragraphs give briefly for each fruit the principal counties and varieties, the usual drying season, and the average drying ratios and yields. 
Apricots.-The counties producing dried apricots are, in order of importance: Santa Clara, Ventura, Riverside, Los Angeles and San Benito. The Sacramento, San Joaquin and Pajaro valleys also contribute large quantities. The principal varieties dried are, in order of importance: Royal, Blenheim, Tilton and Moorpark. To be suitable for drying, an apricot should be of fair size and rich flavor and have a uniform golden color. In the interior valleys, the drying season begins between June 15 and July 1, while in the coast counties picking rarely begins until July 1 to 5 . The acre vield varies from 3 to 9 fresh tons, averaging between 5 and 6 . The drying ratio will vary from as low as $4: 1$ for very large ripe fruit to as high as $7: 1$ for small early maturing fruit, and averages about $5: 1$. The normal yield of dried fruit is from 1 to $1 \frac{1}{2}$ tons per acre. For further information see Circular 238 of this station- "The Apricot in California."

Peaches.-Peach drying is most largely practiced in the Sacramento and San Joaquin valleys. Some peaches are dried in southern California but few along the coast or in the foothills. The leading counties in order of importance are: Fresno, Tulare, Placer, San Bernardino and Solano. Only firm yellow freestone varieties, principally the Muir, Lovell and Elberta, are dried commercially. In the San Joaquin Valley peach drying begins as early as July 15 for Muirs and continues into September for Lovells. In the Sacramento Valley most of the peaches are dried during August. The acre yield may vary from 5 to 20 fresh tons, and averages not over 10 tons. The drying ratio of Muir and Lovell varies from $4: 1$ to $5: 1$, while the Elberta will shrink from $6: 1$ to $7: 1$. A general average drying ratio would be about $5: 1$. The average yield of dried peaches is about $1 \frac{1}{2}$ tons per acre.

Pears.-Bartlett pears, the only variety dried, are grown principally in Sacramento, Solano, Los Angeles, Santa Clara, San Luis Obispo, Yuba and Lake counties. Except in Lake County only pears unsuited to fresh shipment or canning are usually dried. Ordinarily windfall pears, bruised or blemished but otherwise sound are used for drying, but in Lake County a large proportion of the whole crop is dried, which makes this county the leader in quality as well as in quantity of dried pears. In the Sacramento Valley and foothills drying begins about July 15 and extends throughout August, while in the north coast counties it begins during the latter half of August and extends through September. Pears yield from 10 to 20 tons per acre but because of the fact that in most localities only a varying portion of the crop is dried no exact figures for the acre yield of dried fruit can be given. The drying ratio varies from as low as 4:1 in Lake 
County to as high as $7: 1$ in the Sacramento Valley, averaging for the state about $5: 1$.

Prunes.-The greatest prune acreage is to be found in the valleys near the coast, such as those of Santa Clara, Sonoma, Napa and San Benito counties. The acreage in the Sacramento and San Joaquin valleys is rapidly increasing-Tulare, Solano and Butte being leading counties. The most important variety is the French prune. Other important varieties are: Imperial, the largest variety and grown principally in the northern coast counties; Sugar, not so high in quality as the French, but a heavy bearer in the interior valleys; Robe de Sargeant, similar to the French. In the warmer sections, drying begins during the latter part of August and extends through September, but where the prunes are late in maturing drying may commence in September and extend well into October. A prune orchard will produce from 3 to 10 tons of fresh prunes per acre. In the coast counties the drying ratio ranges from $2: 1$ to $21 / 2: 1$ and in the interior valleys and southern California from $2 \frac{1}{2}: 1$ to $3: 1$, the state average being nearly $21 / 2: 1$. The average acre yield of dry prunes is two tons. For further information see Bulletin 328 of this station, "Prune Growing in California."

Figs.-Most of the dried figs are produced in the San Joaquin Valley, the leading counties being Fresno, Tulare, Merced, Stanislaus and Madera. Some figs are dried in the Sacramento Valley, especially Mission figs in Yolo County. The most important variety is the white Adriatic, which is used exclusively for drying. The next in importance is the Calimyrna, which is being extensively shipped and canned as well as dried. The third variety is the Black Mission, the first crop of which is shipped fresh and the second crop dried. The Kadota is used primarily for preserving, but if caprified produces a fair dried product. Figs, especially those which produce two crops, ripen over a long season. The figs drop to the ground when high in sugar and already partially dried and the harvesting season extends from late July to the beginning of cold wet weather in October or even November. Calimyrna orchards produce from 1 to 2 tons and Adriatic and Mission varieties 2 to 4 tons of dried figs per acre, the average for the Calimyrna being 1.2 and for the other varieties 2.5 tons per acre. The drying ratio of figs as normally harvested for drying is lower than that of any other fruit, rarely exceeding $1 \frac{1}{2}: 1$. However, figs picked for fresh shipment or canning would have a drying ratio of about $3: 1$.

Raisins.-Over half the grapes grown in California are of raisin varieties, 95 per cent being produced in the San Joaquin Valley. 
Fresno County, which produces half the world's supply of raisins, omitting currants, is first, followed by Tulare, Kings, Madera and Merced counties. Sutter, Yolo and Yuba counties produce notable quantities of seedless raisins and small quantities are produced in southern California. The varieties used for raisins are, in order of importance: Sultanina (Thompson Seedless), Muscat, and Sultana. Wine and table varieties are dried to some extent, but are generally referred to as dried grapes rather than as raisins. The raisin season extends throughout September and October, according to the time of maturity for a particular variety or district. Good vineyards yield from 5 to 15 tons of grapes per acre. The drying ratio is regulated by the sugar content and may vary from $3: 1$ to $4: 1$, averaging $31 / 2: 1$. The average yield of raisins is from $3 / 4$ to $1 \frac{1}{2}$ tons per acre, although many vineyards produce as high as $2 \frac{1}{2}$ to 3 tons.

\section{PRINCIPLES OF SUN-DRYING FRUIT}

The methods and equipment used in sun-drying fruit are still very much the same as those adopted in the beginning of the industry. Very little scientific study has been given the principles and practices and little exact information has been published. The demand for such information is growing greater and more insistent. Many persons without previous experience are engaging in the growing and drying of fruits and even experienced growers are realizing more than formerly that a thorough understanding of the principles of drying coupled with knowledge of the most successful methods and equipment are essential to the economical production of dried fruits of quality.

If the production of dried fruits in California is to be profitably maintained in spite of constantly increasing production, both domestic and foreign, it is imperative that the quality of our products be of the highest. The individual grower is the most important link in the chain which produces and markets dried fruits and unless he gives the same care to the production of his dried fruit as to the food on his own table, he will not obtain the sale value his product should have. The principles and practices are simple and readily grasped but must be understood and followed in order to get the best results.

Legend for color plate:

Fig. 1.-Types of sun dried fruits (actual size of grades)

1. Muir Peach (Extra Fancy)

2. French Prune $(50 / 60)$

3. Royal Apricot (Choice)
4. Bartlett Pear (Choice)

5. Adriatic Fig (Extra Fancy)

6. Calimyrna Fig (Extra Fancy) 
The writers have supplemented several years of experience in fruit drying by an extensive survey of dry-yards in all sections of the state. Many differences in methods and equipment were noted, some caused by well defined climatic or other conditions while the reasons for other differences were uncertain. The following pages present what may be termed "Standard Methods of Sun-drying Fruits." It is not to be expected that these directions will fit exactly each individual case but it is hoped that they will serve as a general guide for all growers who desire to dry their fruits in the most efficient manner.

\section{RELATION OF CULTURAL PRACTICES TO QUALITY OF DRIED FRUITS}

The quality of dried fruits does not depend alone on the treatment after picking but reflects the management of the orchard or vineyard throughout the year. Conscientious application of the best cultural practices of cultivation, irrigation, fertilization, pruning, etc., is essential to the production of clean fruit of large size and good quality. Proper spraying is often necessary to obtain fruit free from defects due to disease or insect attack. Dried fruit of the larger sizes and fine quality is always in demand at good prices while dried fruit of poor quality and small size is generally difficult to dispose of even at much lower prices. It is important, therefore, that each and every grower exert all reasonable effort toward the production of the best quality, not only for his personal profit, but in order that the markets for California dried fruits may be strengthened and maintained.

Thinning to increase size is a very important operation with apricots and peaches. Small fruit is more expensive to handle, shrinks more in drying and brings a lower price. The following figures furnished by the California Peach and Fig Growers' Association, indicate the financial advantages of thinning. Thirteen peaches (twentysix halves) make one pound of extra fancy dried peaches bringing 17 cents per pound while fifty-four peaches (one hundred and eight halves) are required to make one pound of standard dried peaches bringing only 10 cents per pound. The small peaches contain 7 to 9 per cent of pits while the large peaches lose only 5 per cent in pitting. To produce one pound of dried peaches of standard grade necessitates the picking, cutting and drying of four times as many peaches as are required to produce one pound of extra fancy dried peaches. The cost of cutting "Standards" is about $3 / 4 \mathrm{c}$ per dry pound as compared to $1 / 4$ c per dry pound of "Extra Fancy," and the picking cost for small peaches is half again as great as for large. The smaller sizes, are therefore, more expensive to produce and the price obtained is much lower. 
Comparative observation on the effects of thinning apricots, by Farm Advisor C. C. Staunton of Ventura County in 1923, showed a value for the dried apricots resulting from each box of fresh fruit from the thinned plots of $\$ 1.22$ as compared with 79 cents for the dried fruit from adjacent unthinned plots. This gain of over 50 per cent in value was principally due to the higher prices received for the larger sizes. The unthinned fruit consisted entirely of Standards (the smallest size-grade). The methods of thinning deciduous fruits are described in Circular 258 of this station.

\section{RIPENESS OF FRUIT AND METHODS OF PICKING}

Fruit intended for drying should be thoroughly matured. With the exception of pears, no fruit should be picked for drying until it has developed its full ripe color and flavor and has reached its maximum sugar content. When in prime condition for eating, fruit is also in prime condition for drying but not before.

The hard partially green fruit required for commercial canning or fresh shipment is entirely unsuitable for drying. Such fruit, when dried, yields a product of low grade, lacking in color and flavor, excessively shrivelled and curled up and, because of its deficiency in sugar, always gives a lower yield of dried product. The effect of maturity on the drying ratio of peaches and apricots is illustrated in Table 4. In each case the fruit was picked at one time from a small group of trees at the University Farm, graded for maturity and all lots reduced to the same degree of dryness.

\section{TABLE 4}

Effect of Maturity on the Drying Ratio of Peaches and Apricots

\begin{tabular}{|c|c|c|c|}
\hline \multirow[b]{2}{*}{ Condition } & \multirow{2}{*}{$\begin{array}{l}\text { Blenheim } \\
\text { apricots. } \\
\text { Drying ratio }\end{array}$} & \multicolumn{2}{|c|}{ Muir peaches } \\
\hline & & Drying ratio & Per cent of sugar \\
\hline Soft ripe........ & $4.16: 1$ & $4.86: 1$ & 48.5 \\
\hline Firm ripe........ & $4.50: 1$ & $4.64: 1$ & 48.5 \\
\hline Hard ripe to green.. & $6.40: 1$ & $5.11: 1$ & 45.0 \\
\hline
\end{tabular}

Over-ripeness in fruits that require cutting is also to be avoided because very soft fruit is difficult to cut and dry without losing its shape and forms dark colored "slabs" which stick tight to the trays and bring a low price. 
Pears do not ripen satisfactorily on the tree and they are, therefore, always picked green and allowed to ripen in boxes or bins in the shade. This method results in a firm ripe pear and the best dried product.

Prunes normally drop to the ground when mature but in some sections they may remain on the tree after reaching maturity. In such cases it becomes necessary to knock the fruit to the ground for gathering. Since prunes continue to increase considerably in sugar content until maturity and normal dropping it is advisable to delay knocking as long as possible in order to secure the maximum yield of dark skinned, fine flavored fruit.

The yield and quality of raisins bear a direct relation to the Balling degree (sugar content) of the grape juice. T.o obtain raisins of first quality, Muscat grapes should not be picked below $25^{\circ}$ Balling, or Sultanina grapes below $23^{\circ}$ Balling. The higher the Balling degree of the grapes at picking, the less will be the shrinkage during drying, the greater will be the acre yield of raisins and the higher will be the percentage of the larger sizes, as illustrated by observations on Muscat raisins at the Kearney Vineyard, given in Table 5.

In any case raisin grapes should not be picked for drying until such time as they have attained the highest possible sugar content consistent with safety in completing drying in favorable weather. While the flavor and color of grapes indicate their condition fairly well, the most reliable index of maturity is the sugar percentage of the juice. This is easily and quickly measured by the use of a Balling hydrometer which foats in a sample of the grape juice at a level indicating the percentage of sugar. While a Balling degree of $25^{\circ}$ is most desirable, it is often necessary in certain sections or in certain years to pick the grapes at $22^{\circ}$ to $24^{\circ}$ Balling.

TABLE 5

Relation of Sugar Content of Grapes to the Drying Ratio, Yield and Grades of Muscat Raisins*

\begin{tabular}{l|r|r|r|r|r|r|r}
\hline \hline \multirow{2}{*}{$\begin{array}{c}\text { Balling } \\
\text { degree of } \\
\text { juice }\end{array}$} & $\begin{array}{c}\text { Drying } \\
\text { ratio }\end{array}$ & $\begin{array}{c}\text { Pounds } \\
\text { per acre }\end{array}$ & \multicolumn{5}{|c|}{ Percentage of grades } \\
\cline { 1 - 5 } & & 4 Crown & 3 Crown & 2 Crown & Seedless & Waste \\
\hline 18.6 & 4.6 & 2950 & 7.5 & 66.0 & 23.3 & 1.6 & 2.1 \\
20.2 & 4.3 & 3050 & 7.5 & 68.8 & 21.5 & 1.1 & 1.0 \\
21.8 & 3.9 & 3032 & 8.3 & 70.2 & 19.0 & 1.5 & 1.0 \\
23.6 & 3.6 & 3191 & 12.8 & 68.7 & 15.4 & 2.4 & 0.8 \\
24.0 & 3.5 & 3414 & 20.3 & 64.8 & 13.0 & 1.4 & 0.6 \\
26.5 & 3.3 & 4363 & 30.4 & 56.6 & 12.3 & 0.7 & 0.2 \\
\hline
\end{tabular}

${ }^{*}$ Reported by Professor F. T. Bioletti. 
With the exception of prunes and figs, which generally fall naturally to the ground when mature, fruits should be picked from the tree and not knocked to the ground for gathering. When fruit is knocked or shaken from the tree a certain amount of green fruit is inevitably brought down with the ripe and the fruit becomes more or less bruised and dirty in striking the branches or ground in its fall. When a few very hot days cause the rapid ripening of an entire orchard of apricots, or peaches, hand picking may become too slow, especially if labor is inadequate. Under such conditions it becomes necessary to gather the fruit more rapidly by first knocking it to the ground. Striking the branches with poles may injure the fruit spurs. It is safer to shake each branch by the use of a long pole provided with an iron hook. Small trees can often be sufficiently shaken directly by hand. Experienced pickers can obtain all the ripe fruit by this method without bringing down much green fruit. Where the soil is soft and loose in texture and has been well smoothed before picking, injury to the fruit is minimized. In some sections a large canvas is spread under the tree which not only prevents the fruit from coming into contact with the soil but greatly facilitates transferring the fruit to lug boxes. In general, however, the most successful growers have found that the slightly greater cost of hand picking which makes it possible to exclude immature fruit is overbalanced by the better quality and greater yield of the dried product.

Wind-falls should be picked up frequently, preferably every morning, as the bruised fruit deteriorates very rapidly when lying on the ground in the sun.

\section{PREPARATIONS FOR DRYING}

Cutting.-Pears, apricots and peaches are cut in half and the last two pitted. Halved fruits have become the trade standard because of their superior appearance and the greater readiness with which they may be prepared for the table. Furthermore, halved fruits absorb sulfur fumes and dry much more rapidly than whole fruits. Internal defects caused by split pits, worms, etc., are revealed and such fruits trimmed or discarded.

Cutting is invariably done by hand and should result in two equal halves with cleanly cut, smooth edges. Various types of special cutting and pitting knives have been introduced but possess no advantages over an ordinary sharp knife in the hands of experienced cutters. Cutting machines have been introduced but have not so far been adopted in dry yards. For satisfactory results the fruit must be fed into the machines by hand, after which as in hand cutting the halved fruit must be spread on trays, cut surface up. 
FRUIT DRYING

\section{ORDER OF OPERATIONS}

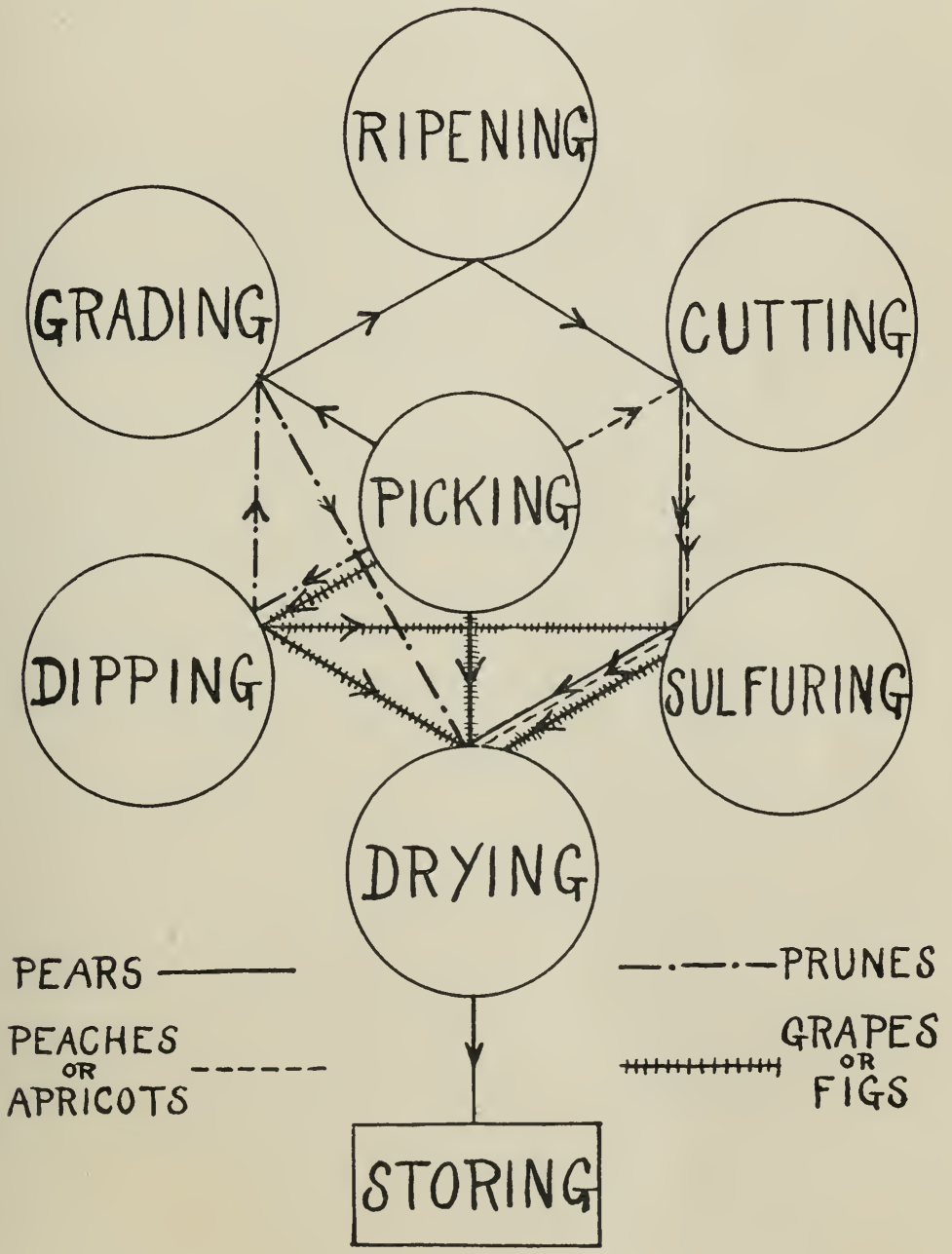

Fig. 2.-Fruit drying, order of operations. 
Apricots can be dried whole after lye dipping and sulfuring but despite their excellent flavor and lower cost of preparation are so far in little demand and bring a comparatively low price. The pits of apricots may be forced out by pressure between the thumb and forefinger after the fruit has been softened by thorough sulfuring but the product is unattractive and of little commercial importance.

Most fruits are not peeled before drying. The fuzzy skin of peaches is preferably removed after drying by a patented process. Peaches may be lye-peeled as for canning or the skins may be slipped off after sulfuring but such peeling reduces the yield and increases the cost of the product.

The pits should be collected and sun-dried. Apricot pits are a valuable source of by-products. An edible fixed oil, the volatile oil of bitter almonds and macaroon paste are being manufactured from the kernels. For this purpose the dry pits have been bringing about $\$ 40$ a ton. Peach pits contain a much smaller percentage of kernels and are not now in demand for by-products but make an excellent fuel which may bring as high as five to ten dollars a ton.

Dipping.-Prunes and some grapes are immersed in a hot dilute alkaline solution for a few seconds before drying. Dipping cleanses the fruit and removes the waxy bloom. This results in a clean, glossy product. The hot alkaline solution produces minute cracks or checks in the skin which greatly facilitate the evaporation of moisture during drying. Ordinarily, grape dipping is largely confined to the Sultana and Sultanina (Thompson Seedless) varieties grown in the Sacramento Valley where it aids in securing rapid and complete drying. If dipping is followed by sulfuring, the sulfur fumes penetrate the fruit more rapidly and completely. Dipping should be followed by rinsing in fresh water to free the fruit from adhering lye solution which is invariably more or less dirty.

White figs are frequently dipped in a cold solution containing salt and sometimes lime. The function of this process is to cleanse the figs and make them moist for more efficient sulfuring.

Sulfuring.-Apricots, peaches, pears, Silver prunes and some grapes are exposed to the fumes of burning sulfur after cutting or dipping and before drying. When sulfur burns it combines with the oxygen of the air to form a gas, sulfur dioxide. This gas has the property of dissolving in water to form a mild acid known as sulfurous acid. This action may be represented graphically as follows.

$$
\mathrm{S}+\mathrm{O}_{2}=\mathrm{SO}_{2}+\mathrm{H}_{2} \mathrm{O}=-\mathrm{H}_{2} \mathrm{SO}_{3}
$$

Sulfur + Oxygen $=$ Sulfur Dioxide + Water $=$ Sulfurous Acid. 
Without the presence of adequate moisture, sulfurous acid cannot be formed in sufficient amounts to secure the desired preserving action on the fruit. For this reason it is highly desirable to wash or sprinkle the fruit with water before sulfuring in order that the surface may be in a moist condition to readily absorb the sulfur dioxide gas. It has also been observed that the higher the temperature naturally obtained in a sulfur house, the more rapid and thorough will be the action of the sulfur dioxide on the fruit.

Sulfurous acid in small amounts is a harmless preservative and without its use the high commercial quality of California dried fruits could not have been developed. Numerous substitutes for sulfur have been tried but none have been successful. Sulfur is the standard and practically the only preservative for dried fruits. Although considerable amounts of sulfurous acid are formed in the fruit during sulfuring the greater part of this is evaporated during drying, and there is a further small but steady loss during storage after drying.

Part of the sulfur dioxide absorbed by the fruit combines with the sugar and other compounds of the fruit in such a way that it cannot be separated from the fruit without destroying the merchantability of the product.

However, if the amount of sulfur burned much exceeds that required to preserve a natural color, an excessive absorption and retention of sulfur dioxide gives the dried product a sulfurous taste which is objectionable to most consumers. Therefore, it behooves every grower to restrict his use of sulfur to the minimum amount found necessary to properly preserve the color of the fruit in order to maintain the good reputation of California dried fruits.

The principal effects of sulfuring are briefly described as follows: It "fixes" or "sets" the natural colors of fruits and prevents darkening by oxidation during drying (see fig. 1). This action is sometimes termed bleaching. This is incorrect, although dark spots on light colored fruits are sometimes temporarily bleached. Sulfuring kills insects and the sulfurous acid prevents fermentation and molding during drying and storage. The absorption of sulfurous acid ruptures the cells of the fruit more or less and draws moisture into the pit cavity. This results in a more rapid evaporation of moisture during drying.

\section{PRESERVATION BY DRYING}

Sun-drying, or the evaporation of moisture by the action of solar heat and natural air currents, is the oldest form of food preservation. Since the beginning of history, fruits, vegetables, cereals, meats and fish have been preserved in the dried form. If properly understood, 
sun-drying is at once the simplest and most economical method of food preservation. By this means vast quantities of fresh fruits ripening during a period of a few weeks are rapidly reduced to a durable concentrated form for subsequent transportation throughout the year to all markets of the world.

A certain amount of moisture is essential to the development of the microörganisms such as yeasts, molds and bacteria which are the cause of spoiling and decay. Fresh fruits contain from 60 to 95 per cent of water and spoil rapidly, but if their moisture content be reduced by evaporation to between 20 and 25 per cent, such spoiling can not occur. In practice, however, growers must dry fruits to a moisture content of 16 to 20 per cent in order that the fruit will be sufficiently dry to permit of the absorption of 5 to 10 per cent moisture during the necessary processing in the packing house, without increasing the moisture content to an amount which permits spoiling. It is not necessary to evaporate all the water in the fruit, because when sufficient water has evaporated that which remains forms with the sugar in the fruit, what may be considered a concentrated syrup. The concentration of sugar becomes so high that it acts as a natural preservative in which microörganisms are unable to develop. If the fruit has been sulfured it may be packed at a higher moisture content because of the added preservative action of the sulfurous acid.

As a result of sun-drying, fruits undergo material changes in color, flavor and texture to which the consumer has become accustomed and which have therefore become the trade standards. No loss of food value results from proper drying.

Evaporation means the change of water from the liquid to the vapor form. The heat required for this change may be obtained by direct radiation from the sun or indirectly from air currents heated by the sun's rays. Without the absorption of a certain definite amount of heat for each pound of water evaporated, drying can not take place. The water vapor driven off by this heat is absorbed by the surrounding air but a given volume of air at a given temperature can only absorb a certain amount of water vapor. This emphasizes the importance of air circulation in removing the partially moisture laden air from immediate contact with the product being dried and in replacing it with drier air so that the air may not become saturated and prevent further evaporation. Summarizing the factors governing sun-drying, it may be said that the rate of drying will be the greater:

1. The higher the temperature of the air,

2. The lower the relative humidity of the air,

3. The more rapid the circulation of the air. 
While in artificial drying these factors can be satisfactorily controlled, little control in sun-drying is possible except that in very hot weather the product may be dried by air currents in the shade, thereby avoiding the more intense heat of the direct sunshine. In sun-drying most of the evaporation takes place during the day since at night the temperature of the air is lower, the relative humidity higher and the amount of air movement generally less.

After preparation, the trays of fruit are nearly always spread on the ground in the direct sunshine for one or more days according to the temperature and the particular practice followed. The first direct exposure warms up the fruit and quickly dries the surface. In addition, the sunlight causes what has been termed an "afterripening" of the color of fruits. This means that a uniform deep rich color is acquired by all the pieces of fruit. Fruit dried exclusively in the shade retains more nearly the original uneven colors of the fruit. Immediately after this first part of the drying, which results in the evaporation of from one to three-fourths of the moisture, the trays are stacked so that the remainder of the drying may proceed more slowly in the shade. This method, known as stack drying, has several advantages. The fruit will often be freer from wind blown dust. Protection from the direct sunshine results in a softer skin and prevents excessive darkening and loss of flavor. Since the final evaporation proceeds more slowly, the dryness of the pieces of various sizes more nearly approaches equality and over-drying, with consequent loss in weight, is avoided.

Drying Ratio.- The term drying ratio is commonly used to designate the relation between the weight of the fresh fruit and the weight of the dried fruit obtained from it. It is expressed as a ratio of the number of pounds of fresh fruit required to produce one pound of dried fruit, as for example, a 5:1 drying ratio for apricots. This ratio includes all losses in weight, chief among which are evaporation of water during drying and losses in preparation such as pitting, trimming, coring, etc. It also includes incidental losses which can be largely eliminated by careful practice. Among these should be mentioned loss of material during preparation; spilling of juice from the cups of sulfured fruits; loss in weight by evapcration of carbon dioxide and alcohol formed by the partial fermentation of sugar during drying of unsulfured fruits. This loss in weight because of fermentation has been found to be considerable in prune drying and is greatly increased by unfavorable drying weather. 


\section{STORAGE AFTER DRYING}

\section{Determining Proper Degree of Dryness.}

The characteristics of fruit when properly dried cannot be explained adequately here and are to be learned by experience rather than from printed directions. In general, however, it may be said that fruit is sufficiently dry when it is no longer soft, puffy or juicy in the center and yet is not so dry and hard as to rattle when the tray is shaken. It should not be possible to separate the skin by hand rubbing. It must be firm and yet uniformly soft and pliable like chamois skin. When a handful of the fruit is squeezed together tightly and then released the individual pieces should drop apart readily. Although it is a fundamental fact that the lower the moisture content the better will be the keeping quality of the dried fruit, excessive drying merely results in a loss of weight and therefore of profit. Since most processing methods necessarily add a little water to the fruit before packing it is obvious that the fruit must be sufficiently dry to absorb this added moisture without exceeding the limits for spoilage.

\section{Equalization of Moisture During Storage.}

It is impossible to have all the pieces of fruit on a tray dried to the same degree at the same time because of the lack of uniformity in the size, composition and preparation of individual fruits. Therefore, when most of the fruit is considered sufficiently dry for storage it is emptied into large boxes or bins to undergo an equalization of moisture, commonly referred to as "sweating." During this process the moisture contents of over-dried and under-dried pieces of fruit are equalized either by direct absorption through contact or by translocation of the moisture by evaporation and absorption. This equalization, which also blends and standardizes the quality of the product, must precede the final processing and packing.

The storage place should be clean, dry, dark, well ventilated and protected from rodents and insects so that the fruit will suffer little or no deterioration during storage. As soon as the necessary equalization has been accomplished, which will usually be within two or three weeks, it is generally advisable to deliver the product at the first opportunity to the packing house for grading and storage.

The processing and packing of dried fruits is ordinarily not conducted by the grower, but is a distinct and separate operation conducted in large centrally located packing houses by persons experienced in the methods. This phase of the industry is not described in this publication. 

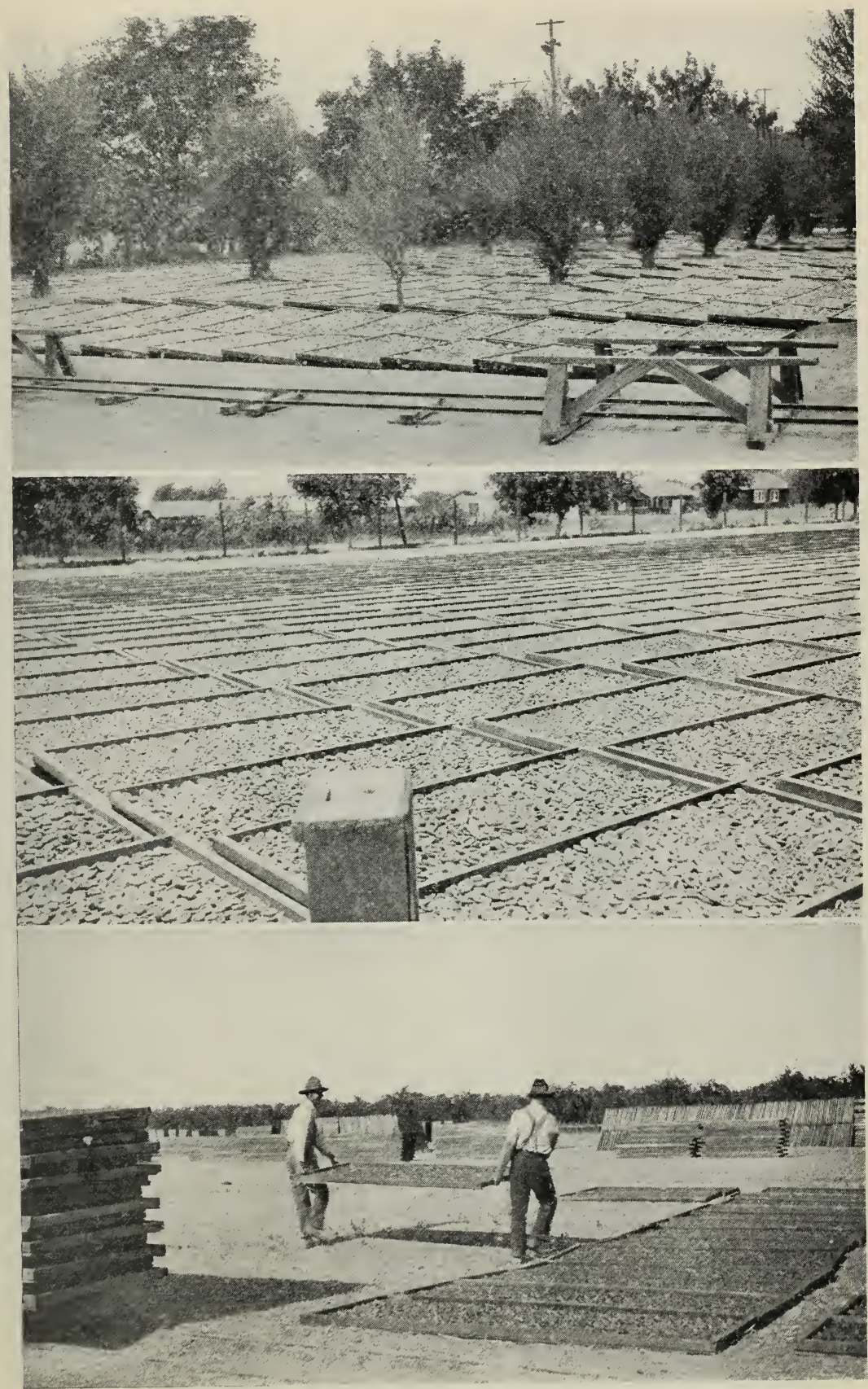

Fig. 3.-Typical dry yard scenes. 


\section{EQUIPMENT FOR SUN-DRYING FRUITS}

\section{DRY YARDS}

With the exception of undipped grapes which are dried between the rows in the vineyard and some figs which are cured in the orchard, all fruits are brought to an open dry-yard for preparation and drying. The concentration of all operations at one place set aside for the purpose is economical of time and labor.

The dry-yard should be conveniently located with respect to the orchard or vineyard and away from all dusty roads and barn yards. Roads required for hauling fruit to and from the dry-yard should be so located that the prevailing winds will blow the dust away from and not over the drying fruit. The dry-yard should have a sunny exposure free from shading trees, and preferably a slight slope toward the south. Larger yards where cars and tracks are needed should be sufficiently level to permit their use. The area of dry-yard required will vary from one-third to one acre for each ten acres of orchard or vineyard; according to the orchard yield and the speed of drying. In general, 1 to 20 is a safe average ratio.

The surface of the ground should be handled in such a way as to prevent dust blowing on the fruit during drying. Some excellent dryyards, as illustrated in fig. 3, are never cultivated but the ground is allowed to become solidly packed and free from loose dust or vegetation. A more common practice is to grow grain or hay and spread the trays on the closely cut, well raked stubble after harvesting. This usually necessitates the relaying of portable tracks each year, but realizes a return from the crop harvested. The stubble should never be burned before the drying season as this causes the fruit to become unsightly because of wind blown bits of charred straw. A closely cut and not recently irrigated alfalfa field is very satisfactory for peaches and apricots but for the slower drying prunes or grapes in cooler sections may unduly increase the drying time. The contamination of dry-yards and drying fruit by animals or poultry must be carefully guarded against by adequate fencing.

Foreign matter which lodges on the surface of cut fruits during drying can not be satisfactorily removed in the packing house and, therefore, seriously lowers the quality of the product. Consequently the dry-yard should be so prepared and managed as to minimize contamination of the fruit during drying. 


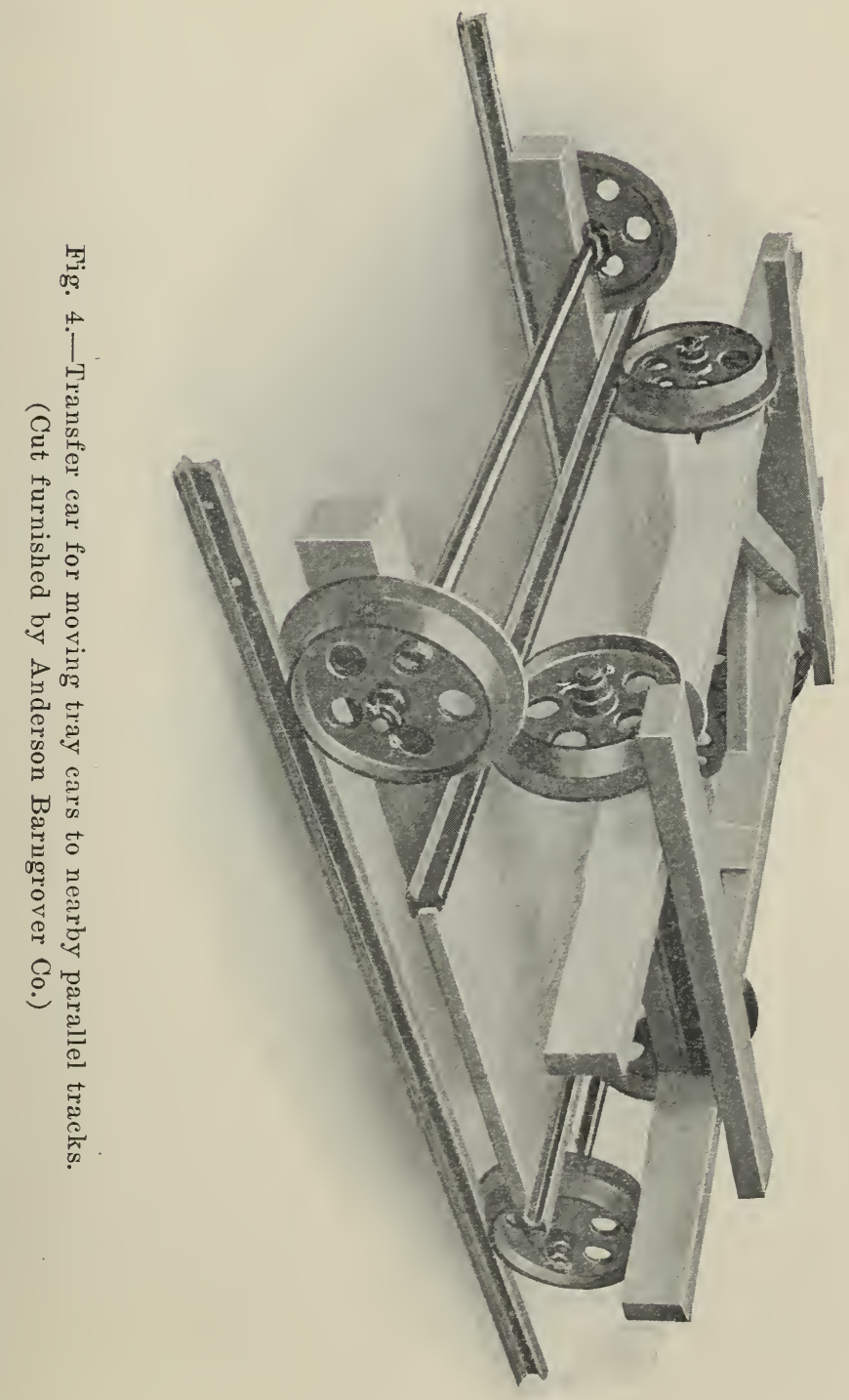


All but the smallest yards should be provided with a system of tracks and ears for moving the trays of fruit between the various steps in preparation as well as to and from the spreading ground. Hand carrying or the use of a horse and wagon are generally less economical and sanitary. Miniature steel railroad tracks with either steel or wooden ties are the most substantial and permanent, although wooden rails, if faced with strap iron or angle iron, are satisfactory. Such tracks may be either permanently installed or portable but in either case should be smoothly laid so that the juice in the cups of freshly sulfured peaches and apricots is not spilled during transportation. The arrangement of tracks with respect to the dipping or cutting shed, sulfur houses, dry-yard and dried fruit storage space should be such that the fruit moves forward steadily through the various operations with the minimum retracing of routes. Empty trays and cars should be returned to the reloading point without coming in contact with loaded ears. The amount of trackage must be determined by the quantity of fruit handled daily and the area and shape of the dry yard.

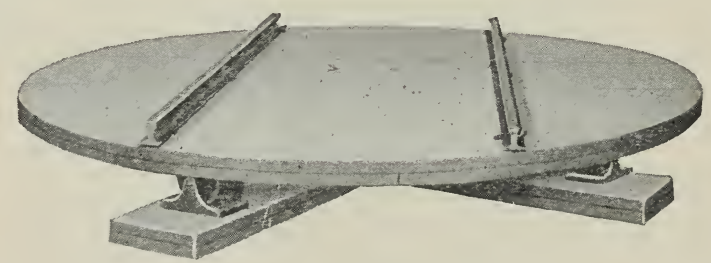

Fig. 5.-Turntable for changing direction of tray cars. (Cut furnished by Anderson Barngrover Co.)

The usual type of tray car, as illustrated in fig. 4, consists of a low wooden frame about $3^{\prime} \times 6^{\prime}$, supported by four cast-iron wheels on steel axles. Such cars will carry from 20 to $253^{\prime} \times 8^{\prime}$ trays holding from 1000 pounds of apricots to 2000 pounds of prunes. In order to provide the necessary flexibility in the transportation system as in moving cars in and out of sulfur houses and to various parts of the dry yard, use is made of steel or wooden transfer cars or of turn tables sunk below the standard track level so that the tray cars can be run on them for movement at right angles to their previous direction (see figs. 4 and 5).

Figure 6 shows a suitable arrangement for a $2 \frac{1}{2}$ acre dry-yard equipped to handle cut and sulfured as well as dipped fruits. It is not expected that this plan will fit all conditions but should serve as a guide in planning a well arranged dry-yard. 


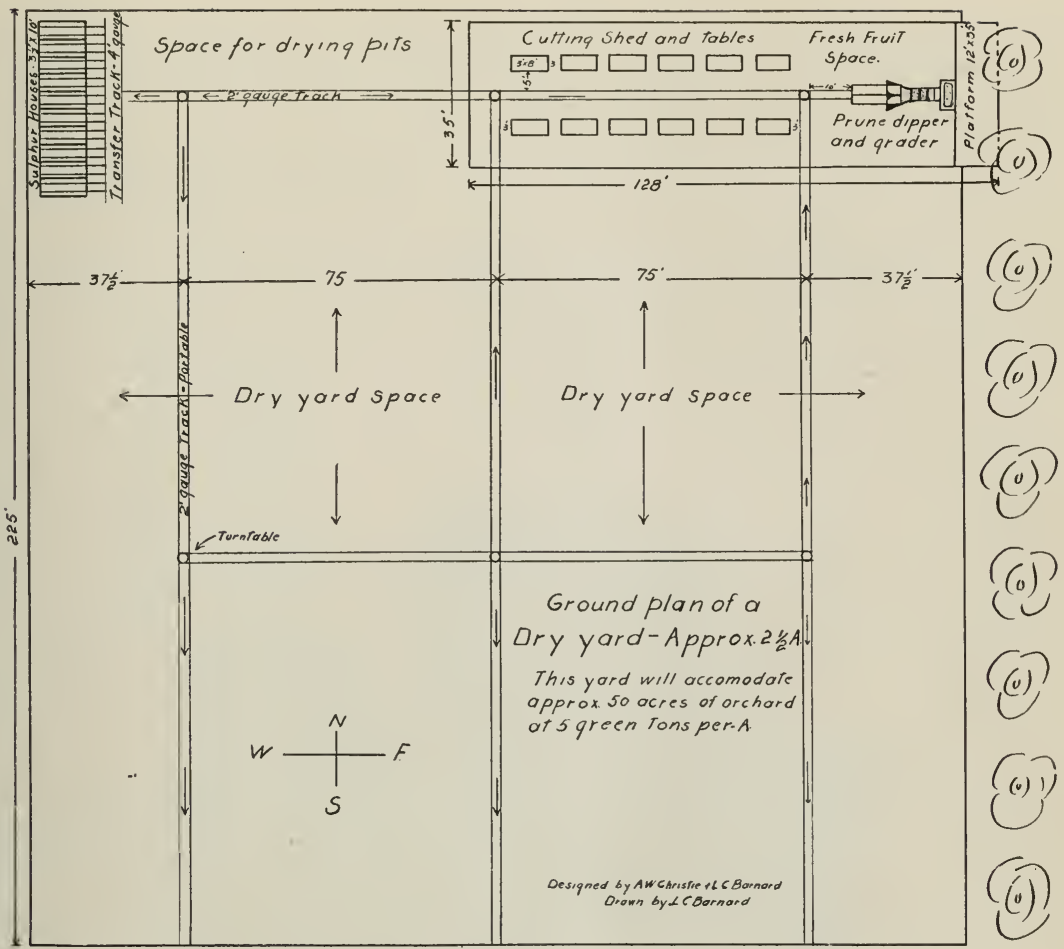

Fig. 6.-Ground plan of a dry-yard.

\section{CUTTING SHEDS}

While small quantities of fruit are frequently cut and trayed under the shade of trees adjacent to the dry-yards, the use of an inexpensive shed is generally desirable, not only to protect the cutters and the fruit during preparation but to serve as a convenient storage place for trays, boxes and other equipment during the winter. For most orchards an open shed, with a tight roof, sufficiently large to accommodate the number of cutters employed, is adequate. It should be so located that prevailing winds will not blow fumes from the sulfur houses toward it and may be walled on one or more sides to give protection from wind-blown dust or sulfur fumes. Ample light and ventilation are necessary for efficient work by the cutters.

The fruit is unloaded at one end or side of the shed and carried to the cutting tables as required. An inexpensive and convenient cutting table, designed to hold one $3^{\prime} \times 8^{\prime}$ tray or several smaller trays and provided with brackets on both sides to hold boxes of fruit for 
cutting, is shown in fig. 7. The track for loading cars should be adjacent to the rows of tables so that each tray as it is filled may be placed on a car and replaced by an empty tray. The floor of large

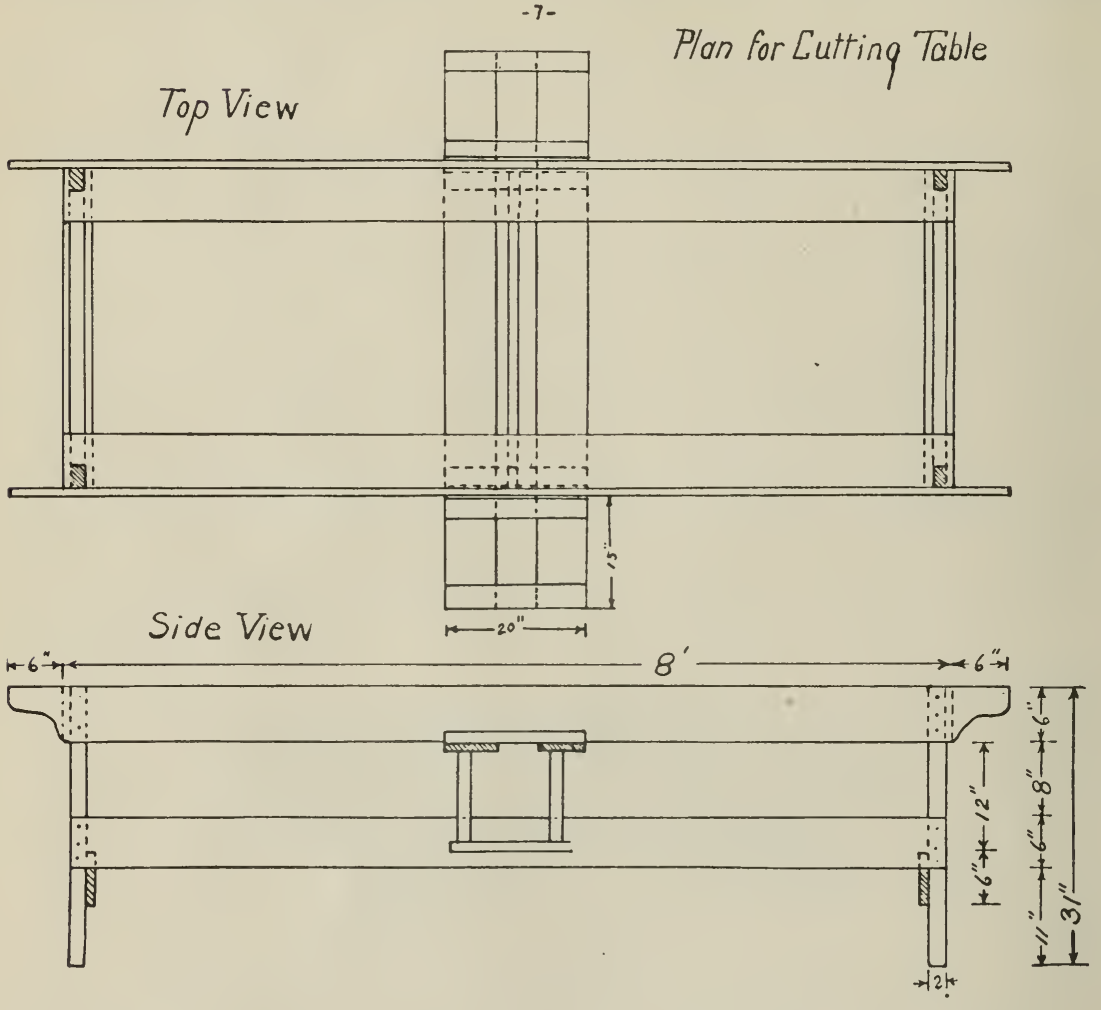

End View

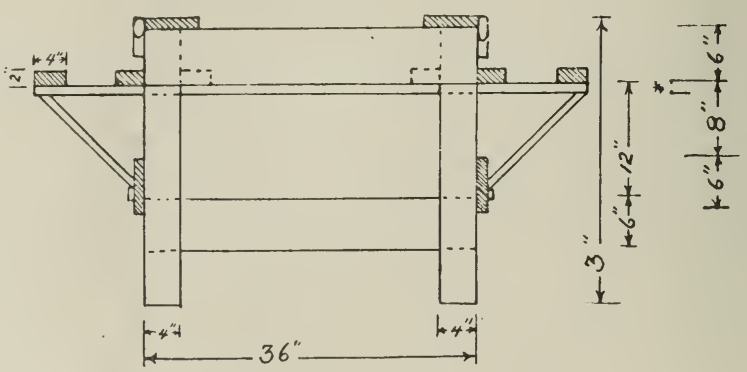

Fig. 7.-Plan for fruit cutting table.

sheds where much trucking is necessary should be of wood or concrete but in small sheds the natural ground may be used if sprinkled daily to prevent dust rising. The comfort afforded cutters by stools results 
in greater efficiency. Sharp knives and small pans or boxes for the collection of pits and spoiled fruit are necessary to secure cleanly cut fruit. Water, soap and paper towels should be provided so that the cutters may frequently wash their hands and knives. Sanitary toilets and drinking fountains are sanitary requirements. A small supply of iodine, bandages and adhesive tape is necessary "first-aid" equipment for cuts or scratches. Cards on which are marked or punched

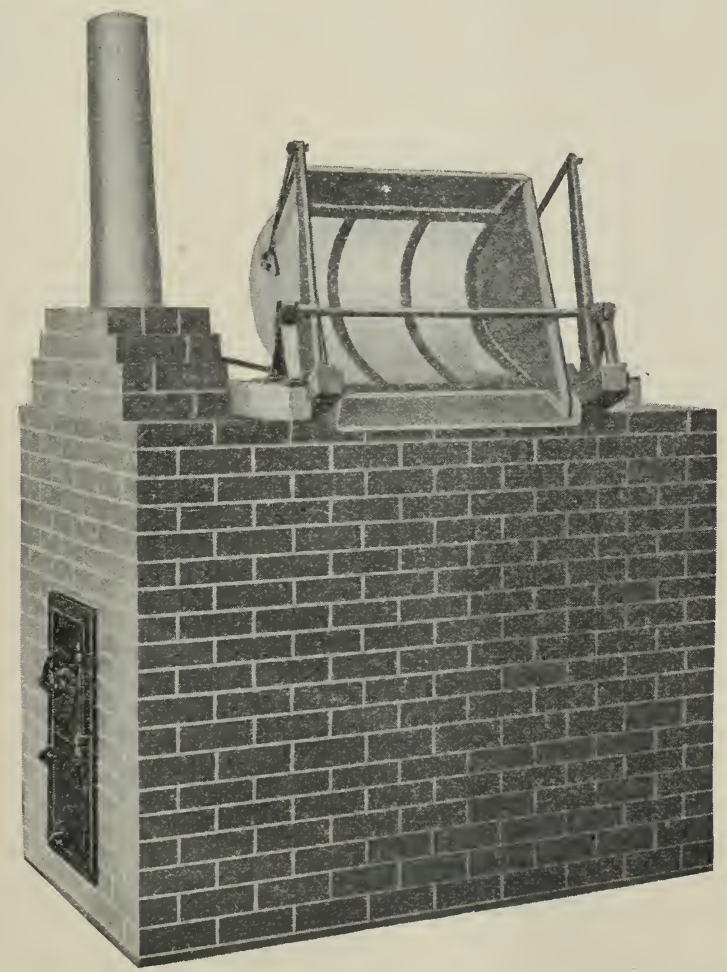

Fig. 8.-Dump basket, prune or grape dipper, with lye tank and furnace.

(Cut furnished by Anderson Barngrover Co.)

the number of boxes of fruit cut by each person daily furnish a simple and invaluable record of the payment due to cutters and of the amount of fruit handled. In fairness to the cutters and as a record of the amount of fruit picked and cut each box should be made up to the same net weight before cutting.

\section{DIPPERS}

Basket dippers are used for both grapes and prunes. The simplest type illustrated in fig. 8, consists of an oblong basket with a rounded bottom of perforated sheet metal or wire screen. This basket is hinged 
to one edge of the lye tank so that after immersion the basket may be raised by a lever, the fruit drained and emptied directly on to the tray or into a small bin or a shaker which in turn discharges on to the trays. Another type, known in Sutter County as the "Merry-goround," and used especially for Sultanina (Thompson Seedless) types, suspends the basket from an over-head counterbalanced beam which is fastened to a pivoted upright. The fruit is emptied into the basket at one point, the basket swung over the lye tank and submerged, removed from the lye tank and swung to the other side for discharging the grapes on to the trays. If two opposite baskets are used, loading and unloading may proceed simultaneously, the baskets describing a complete circle for each load. Continuous automatic dippers consisting either of an endless draper or a series of baskets supported by two endless chains, are used in a few of the larger grape dry-yards.

Rotary Dippers are used only for prunes and consist of a rotating perforated metal cylinder the lower third of which is submerged in the lye solution. The prunes are emptied in at one side and, by means of vanes set at the proper angle on the inner walls of the drum, are carried down through the lye solution and discharged at the opposite side. These dippers, illustrated in fig. 9, are automatic and continuous and have the greatest capacity. They are operated by a gas engine or electric motor and the speed of rotation can be varied to regulate the time of immersion. Rotary dippers can be provided with a vibrating screen on which the prunes are emptied for separation of dirt and leaves, before entering the dipper. This results in cleaner fruit and prevents the lye solution becoming dirty so rapidly.

Lye tanks have a capacity of from 100 to 200 gallons and are mounted in a rectangular brick furnace. Wood is used by some as a source of fuel but the majority use some of the forms of oil burner because they can be made to maintain a constant temperature with very little attention. The less expensive natural draft burners require a refined oil such as kerosene while forced draft burners utilize the less expensive stove oil or even crude oil. In a few places the lye tank is heated by steam coils but this system is not recommended unless a steam boiler is required for other purposes.

\section{LYE}

The lye used in dipping is sodium hydroxide or "caustic soda." The commercial product, granulated or in flakes, contains 95 per cent or more of sodium hydroxide, the active ingredient. It should be kept in tight metal containers to prevent absorption of moisture from the air. Some brands of "lye" consist partly of sodium carbonate or 


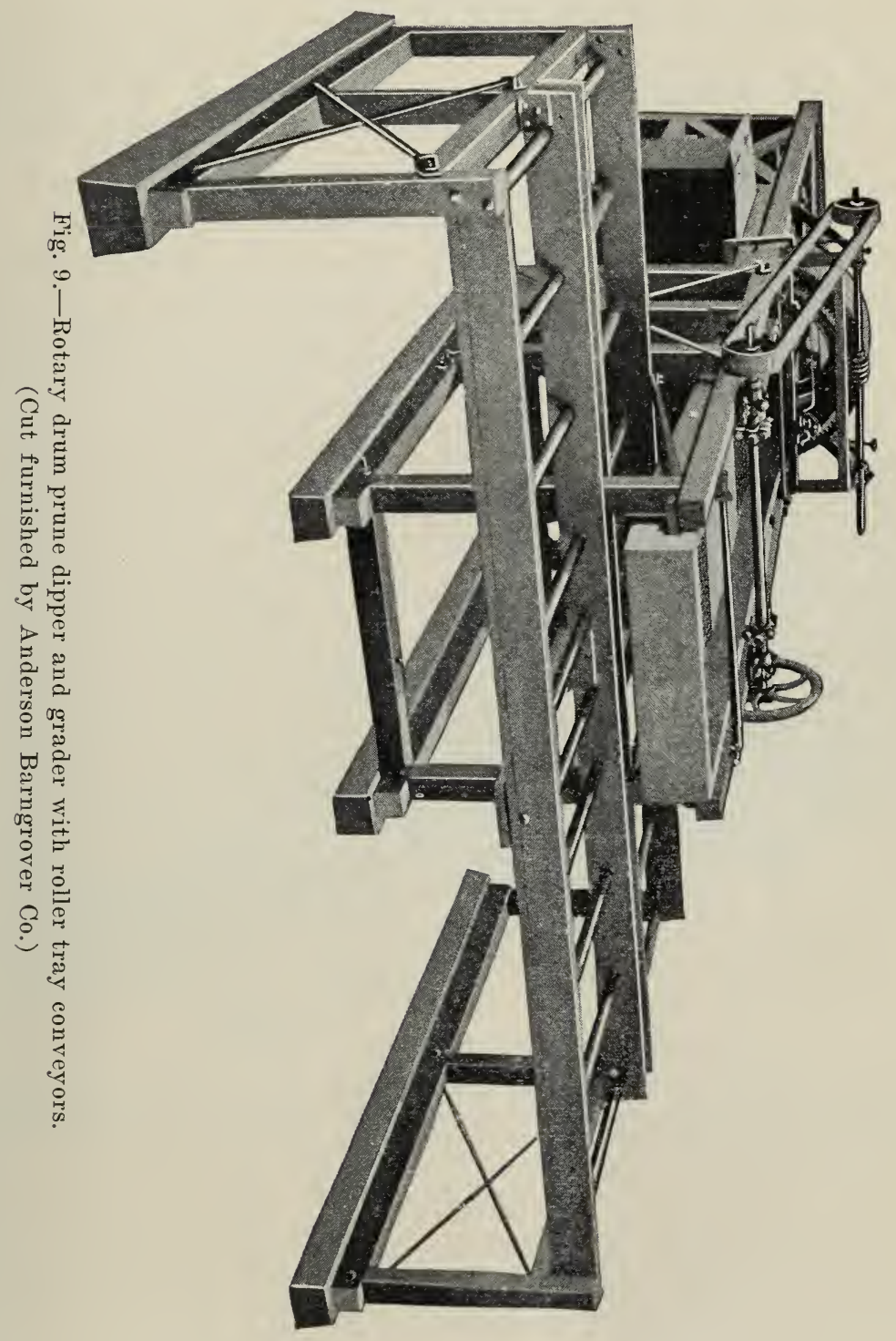


"sal soda," a compound which is not so strongly alkaline as sodium hydroxide but gives equally satisfactory results if used in sufficient strength. The stronger sodium hydroxide is preferred for prunes, while the milder sodium carbonate either alone or in combination with sodium hydroxide is largely used on the more easily affected Sultanina (Thompson Seedless) grapes. Sodium bicarbonate or "baking soda"" is another and much weaker alkaline salt which is used in the dipping of "oil bleached" raisins.

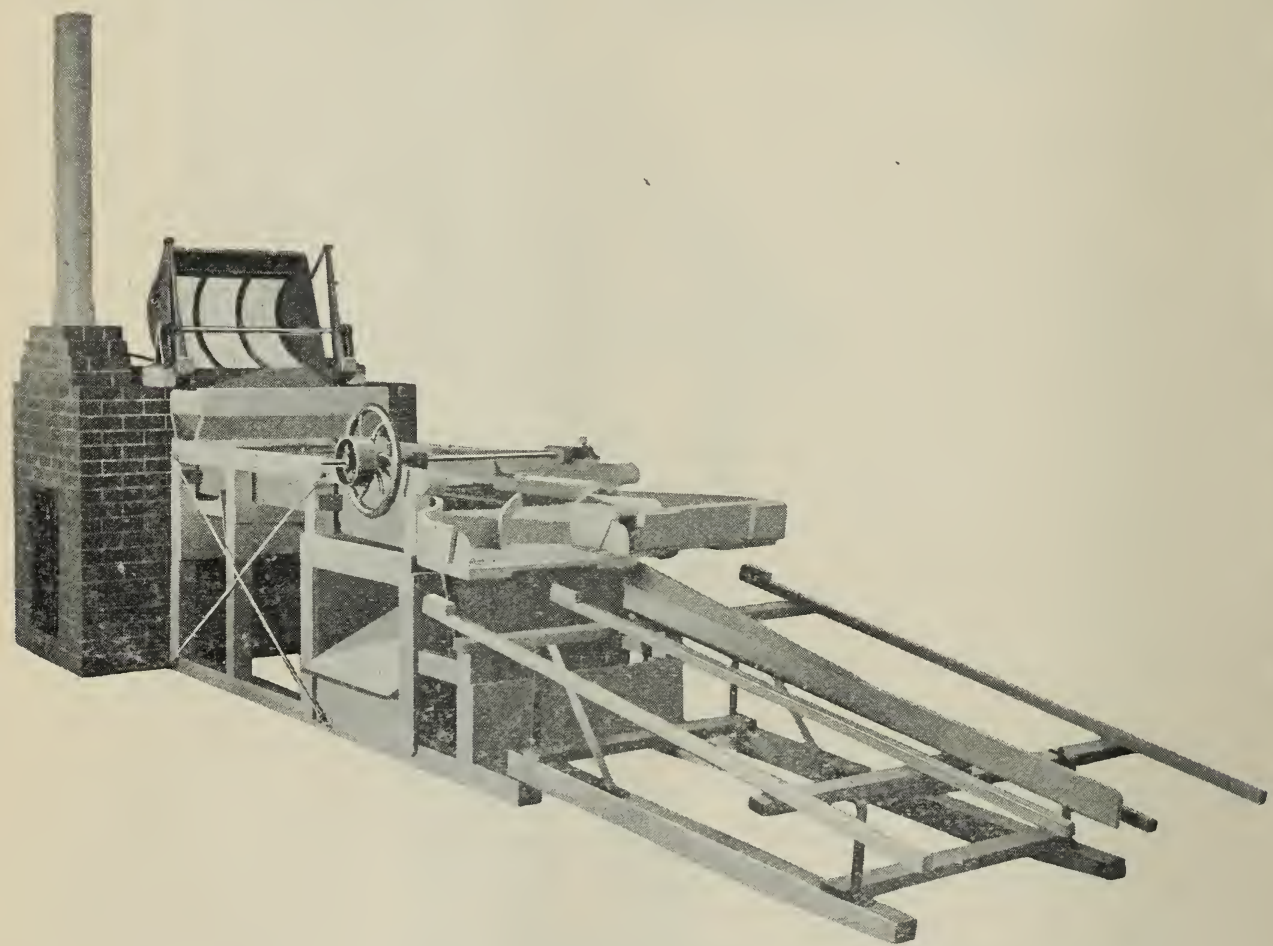

Fig. 10.-Hand-operated basket prune dipper, with lye tank and furnace, connected to power-driven grader. Tray supports in foreground. (Cut furnished by Anderson Barngrover Co.)

\section{GRADERS}

Graders are used in conjunction with most of the larger prune dippers. The dipped prunes are separated into two or three sizes by passing over vibrating screens which ean be changed to suit the sizes desired. This so-called "green grading" is valuable in securing more even drying by placing the small and large prunes on separate trays. If grading is not done, the small prunes may be over dried when the large ones on the same tray are still too moist. This necessitates extra trays and sorting. A small grader is illustrated in fig. 10. 
Needle boards are often incorporated with graders. They consist of a flat vibrating board or sometimes a rotating cylinder, each studded with short sharp needles, and are frequently used to supplement the dipping of prunes. When prunes of varying degrees of maturity are dipped together, the skins of those which are not checked by the lye solution are at least punctured by the needles, providing apertures for the rapid and even evaporation of moisture.

\section{TRAYS}

The most common sizes of trays used are the $2^{\prime} \times 3^{\prime}, 3^{\prime} \times 6^{\prime}$ and $3^{\prime} \times 8^{\prime}$, illustrated in fig. 11. Other sizes have no special advantages and are seldom used. The $2^{\prime} \times 3^{\prime}$ tray is referred to as the raisin tray because it is universally used in the natural drying of raisins in the vineyard. In the raisin sections it is also used for peaches, apricots and figs. The $3^{\prime} \times 6^{\prime}$ tray is used for peaches, apricots, figs and dipped grapes, especially seedless. It is also used for prunes and pears although in Lake County a special tray, $2 \frac{1}{1} 2^{\prime} \times 7^{\prime}$ is preferred for pears. The $3^{\prime} \times 8^{\prime}$ tray is preëminently the prune tray but is also used for peaches, pears and apricots. Table 6 gives the usual specifications, capacities and costs of the standard trays. It must be borne in mind that the weight of fruit which can be spread in a single layer on one square foot of tray surface varies considerably with the size of the individual pieces of fruit. Unless below average size, apricots can be spread at the rate of two pounds and peaches three pounds per square foot. Pears and prunes vary from three to four pounds per square foot but not usually less than three and one-half pounds. Muscat grapes do not fall below three and one-half pounds per square foot but seedless grapes are usually spread about three pounds per square foot.

The number of trays required to sun-dry a given tonnage of fruit during the season varies greatly with the rapidity with which the fruit ripens and drys. Prune and raisin trays are generally used but once each season and it is therefore necessary to have sufficient trays to spread the entire crop. Trays for peaches and apricots are generally used two or three times during the season and the number required is proportionately less. In estimating the number of trays required to dry the fruit from a given acreage, the tonnage of fruit per acre becomes another factor of variation. Table 7 gives the approximate number of standard trays required to dry various fruits. Such figures are subject to great variation but the limits stated in Table 7, cover most cases. 


\section{SCANDAPD TYDES OF FRUIC CDAYS}

Scale : $-1 /$ in. $=1$ ft.
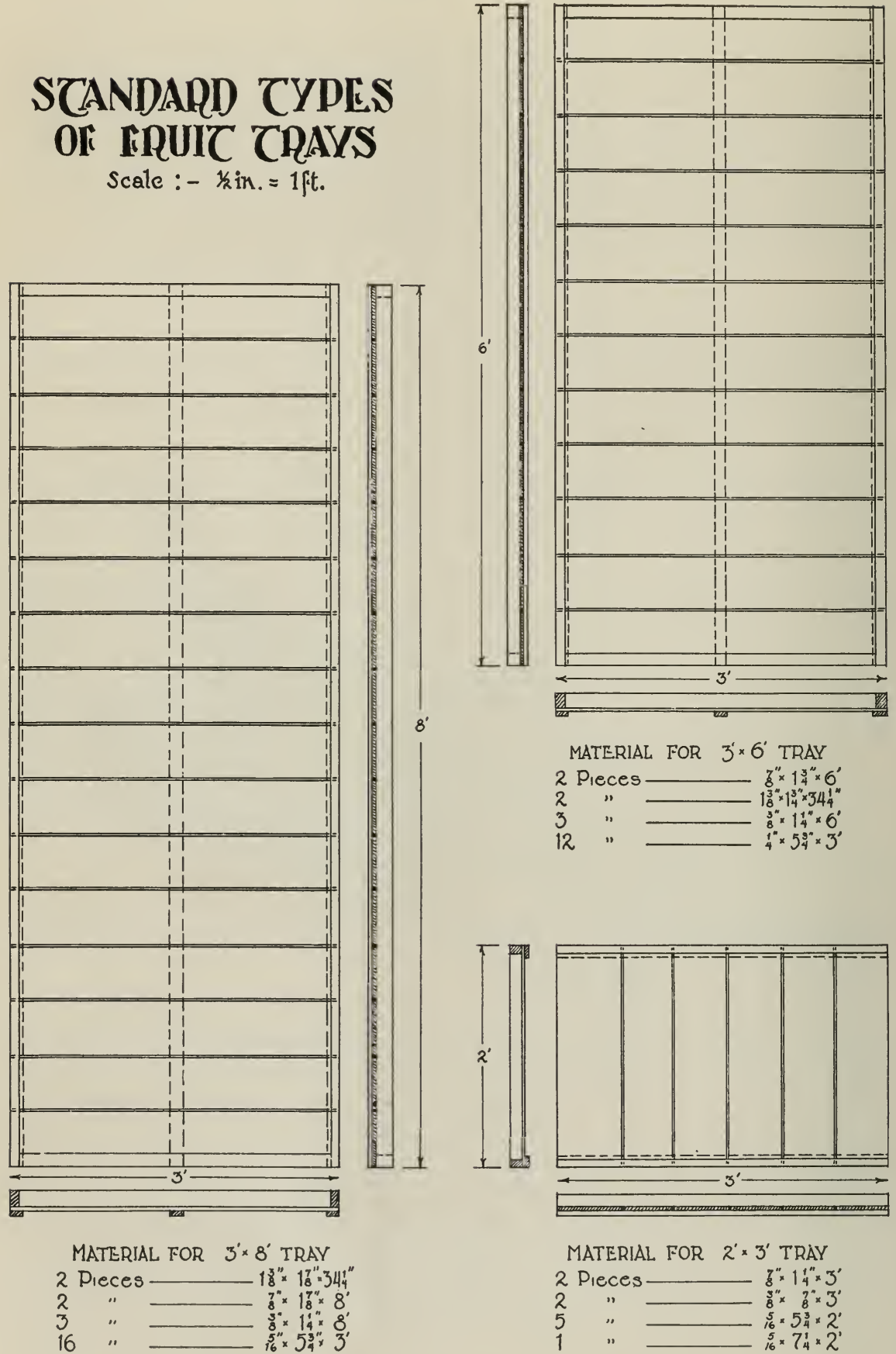

\section{MATERIAL FOR $Z^{\prime} \times 3^{\prime}$ TRAY}

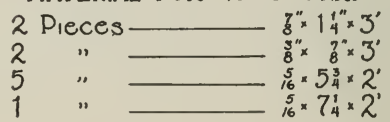

Fig. 11.-Standard types of fruit trays. 
TABLE 6

Specifications, Capacities and Costs of Standard Field Trays

\begin{tabular}{|c|c|c|c|}
\hline Standard specifications & $2^{\prime} \times 3^{\prime}$ Trays & $3^{\prime} \times 6^{\prime}$ Trays & $3^{\prime} \times 8^{\prime}$ Trays \\
\hline End cleats... & $2-7 / 8 " x 1 \frac{1}{4}{ }^{\prime \prime} \times 3^{\prime}$ & $2-13 / 8^{\prime \prime} \times 1 \frac{3}{4}$ " $^{\prime \prime} 341 / 4$ " & $2-13 / 8$ "x17/8"x341/4" \\
\hline Side cleats.... & $2-3 / 8^{\prime \prime} \times 7 / 8^{\prime \prime} \times 3^{\prime}$ & $2-7 / 8^{\prime \prime} \times 13 / 4^{\prime \prime} \times 6^{\prime}$ & $2-7 / 8{ }^{\prime \prime} \times 17 / 8{ }^{\prime \prime} \times 8^{\prime}$ \\
\hline Clinch cleats... & & $3-3 / 8^{\prime \prime} \times 1 \frac{1}{4} 4^{\prime \prime} \times 6^{\prime}$ & $3-3 / 8^{\prime \prime} \times 11^{\prime \prime} \times 8^{\prime}$ \\
\hline Bottom boards... & $\begin{array}{l}5-5 / 16 " \times 53 / 4 " x 2^{\prime} \\
1-5 / 16 " \times 71 / 4^{\prime \prime} \times 2^{\prime}\end{array}$ & $12-1 / 4^{\prime \prime} \times 53 / 4^{\prime \prime} \times 3^{\prime}$ & $16-5 / 16{ }^{\prime \prime} \times 5^{3} / 4^{\prime \prime} \times 3^{\prime}$ \\
\hline Gross area in sq. ft..... & $6^{\prime}$ & $18^{\prime}$ & $24^{\prime}$ \\
\hline Average capacity in lbs.: & & & \\
\hline 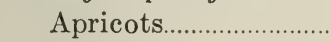 & $10-12$ & $30-36$ & $40-48$ \\
\hline Figs...................... & $13-17$ & $40-50$ & $53-67$ \\
\hline Grapes. & $18-22$ & $54-66$ & $72-88$ \\
\hline Peaches............. & $15-20$ & $45-60$ & $60-80$ \\
\hline Pears.............. & $18-24$ & $54-72$ & $72-96$ \\
\hline Prunes.............. & $18-24$ & $54-72$ & $72-96$ \\
\hline Approximate cost: & & & \\
\hline Made up.... & \$. 20 & $\$ .78$ & $\$ 1.00$ \\
\hline
\end{tabular}

TABLE 7

Number of Trays Required for Sun-Drying*

\begin{tabular}{|c|c|c|c|c|c|c|}
\hline & \multicolumn{2}{|c|}{$2^{\prime} \times 3^{\prime}$ Trays } & \multicolumn{2}{|c|}{$3^{\prime} \times 6^{\prime}$ Trays } & \multicolumn{2}{|c|}{$3^{\prime} \times 8^{\prime}$ Trays } \\
\hline & Per ton & Per acre & Per ton & Per acre & Per ton & Per acre \\
\hline Apricots... & $30-45$ & $150-500$ & $10-15$ & $50-166$ & $8-11$ & $38-125$ \\
\hline Figs............ & $15-20$ & $30-40$ & $5-7$ & $10-13$ & $4-5$ & $8-10$ \\
\hline \multicolumn{7}{|l|}{ Grapes: } \\
\hline Muscat... & $90-100$ & $315-350$ & $30-33$ & $105-117$ & $23-25$ & $80-88$ \\
\hline Sultanina.. & $110-120$ & $520-570$ & $37-40$ & $173-190$ & 28-30 & $130-143$ \\
\hline Peaches........... & $35-45$ & $260-340$ & $12-15$ & $87-113$ & $9-11$ & $65-85$ \\
\hline Pears............. & $40-80$ & $200-400$ & $13-27$ & $65-130$ & $10-20$ & $50-100$ \\
\hline Prunes........ & $44-60$ & $220-760$ & $15-20$ & $73-253$ & $11-15$ & $55-190$ \\
\hline
\end{tabular}

* Calculated from observations on seasonal tray requirements for given tonnages and acreages of fruit.

Pine is the most common kind of wood used for trays. Trays with spruce frames and pine bottoms are considered by some to be more sturdy and longer lived. Redwood is used in some sections because of its lower cost. Redwood trays, especially when new, have been known to stain moist light colored fruits such as peaches, pears and apricots but are satisfactory for prunes. In constructing trays the rougher side of the bottom boards should be up because dried fruit 
sticks less and is more easily removed from rough than smooth surfaces. Heavy wrapping paper obtainable in bundles of 2 reams or 960 sheets is used for drying raisins in the vineyard when wooden trays are unavailable. Paper trays are less suitable because raisins can not be properly turned or stacked on such trays and in case of rain may result in the loss of raisins because the wet paper can not be handled. Furthermore, paper trays hold less grapes, more are spilled on the ground and more dirt incorporated with the raisins. Although lower in first cost (about 1 cent each), paper trays must be replaced yearly and are, therefore, if we consider decrease of quality and losses from rain damage, more expensive in the long run than permanent wooden trays.

Clean trays are necessary for the production of clean dried fruit. If trays become dusty, sticky or moldy they should not be used until they have been washed and dried. If properly handled such washing is generally necessary only at the close of each season. The use of a stiff bristle or wire brush will remove all dirt after it has been softened by immersing the tray in a hot solution containing sal soda. After rinsing, the trays should be sulfured and thoroughly dried to prevent molding during storage. It is preferable to store trays in some sort of building or shelter which keeps the trays clean and dry and by protecting them from the weather lengthens their useful life.

\section{SULFUR HOUSES}

Many types and sizes of sulfur houses, varying in their cost and efficiency, are in use. The simplest and cheapest type is known as the sulfuring "hood" and consists of a light wooden framework covered with building or roofing paper (see fig. 12). It is open at the bottom and of such a size that two men can lift it up by the handles and place it over a stack of trays on the ground. The sulfur is burned in a hole in the ground or preferably in a pan or bucket set on the ground inside one end of the hood which should be made at least a foot longer than the stack of trays. Earth is shoveled against the bottom of the hood to prevent escape of sulfur fumes. Such hoods are highly inflammable, not very tight, and their useful life is limited to a few seasons. Their use is not recommended except in emergencies or for very small scale operations.

The most common sulfur house is built of wood made as tight as possible either by the use of tongue and groove lumber or by common boards lined with building or roofing paper. A tight fitting door at 
one end permits the entrance of a truck of trays which is rolled into the house on tracks. Houses of concrete, brick or hollow tile are always tight and fire-proof (see fig. 13) but are not recommended for the efficient sulfuring of fruit with the minimum amount of sulfur because of the retarding influence of the cold air resulting from the resistance of these materials to heat penetration. Heavy beveled doors with locks of refrigerator type are the best.
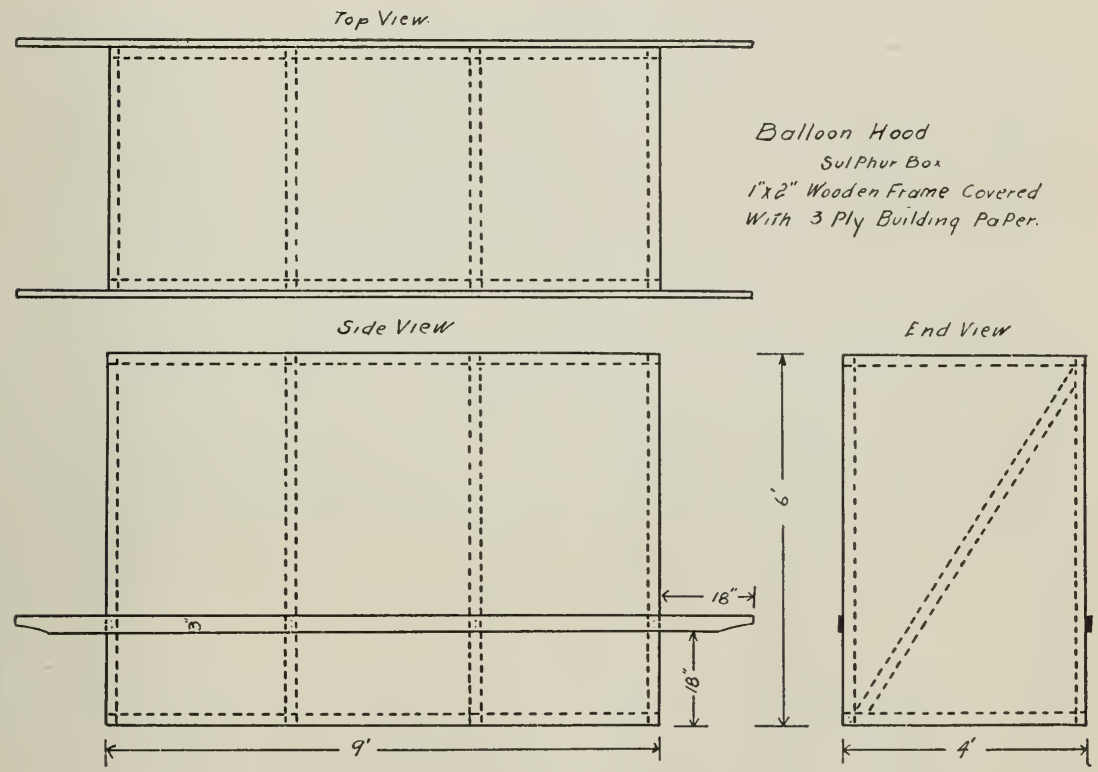

Fig. 12.-Balloon hood sulfur box.

For efficiency and economy in sulfuring, the main essentials of sulfur house construction are:

1. Tight construction to prevent leakage of sulfur fumes.

2. Materials of construction which permit warming the interior by penetration of solar heat.

3. Adequate space and protection for the sulfur burning equipment to minimize fire hazard.

Recent investigations by R. S. Hiltner, Technologist of the Dried Fruit Association of California indicate that a sulfur house built of flat sheet iron painted outside and inside with black asphalt paint to resist rust and corrosion fulfills the above requirements. 

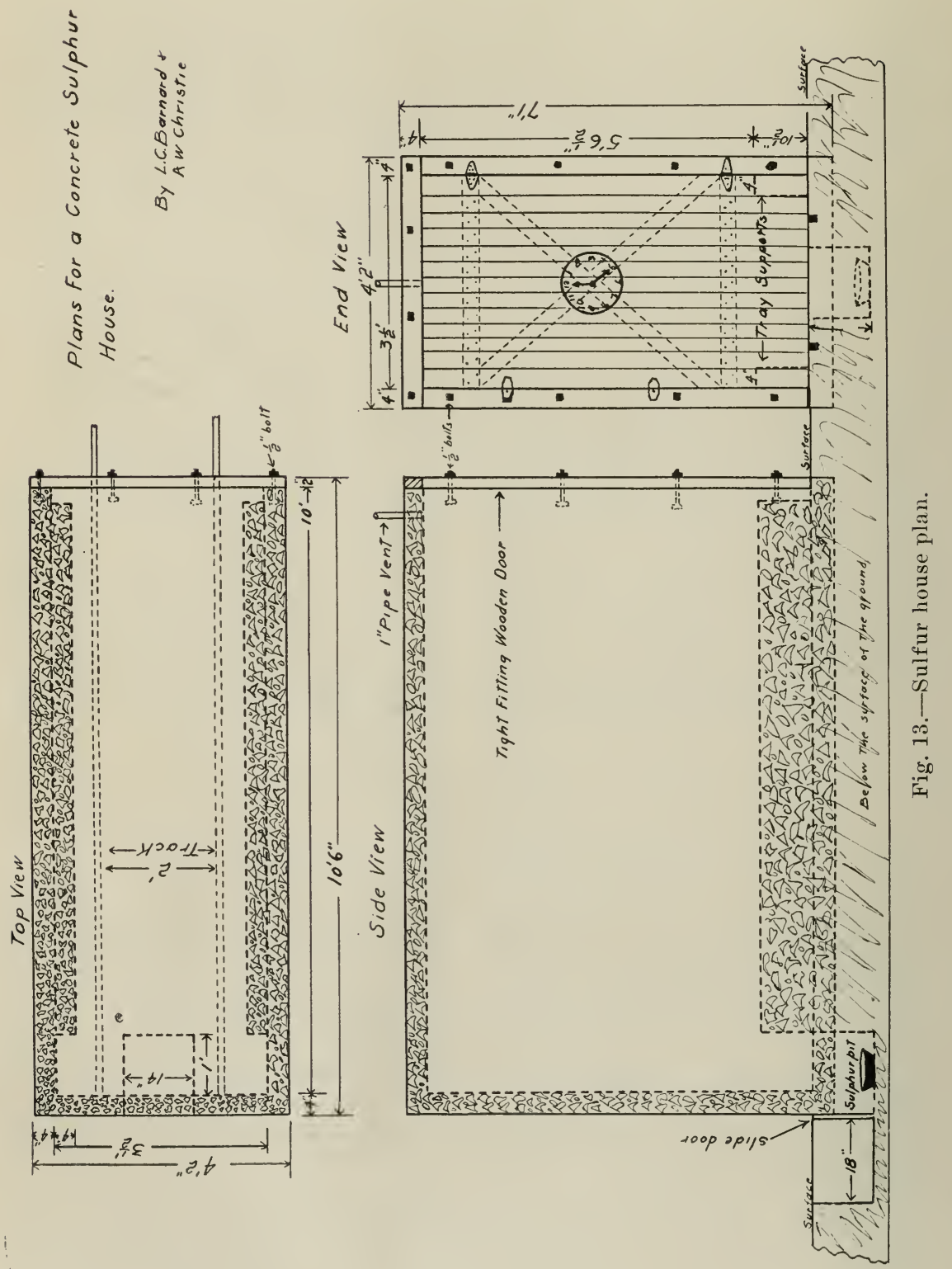
Common sulfur houses as illustrated in figs. 14 and 15, are usually a little over 3 feet wide and 6 to 7 feet high inside. The length should be about 2 feet more than that of the car of trays, to provide space for burning sulfur. A number of houses sufficient to accommodate the

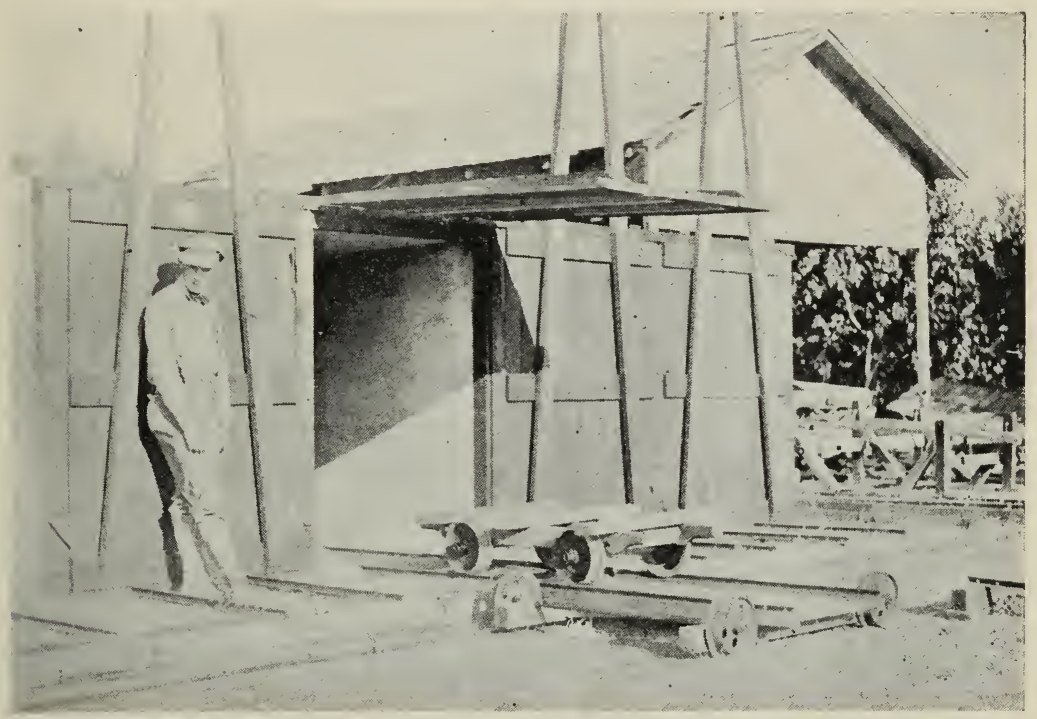

Fig. 14.-Typical sulfur houses with counterpoised door hinged at top. Note transfer and tray ears.

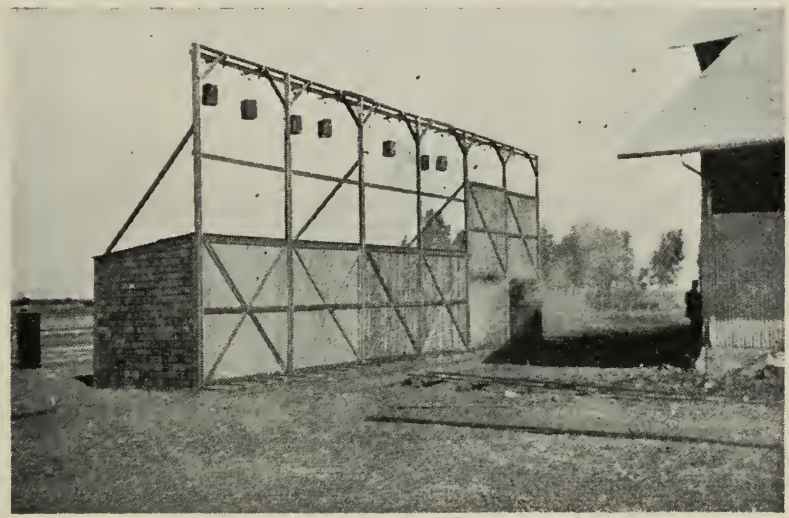

Fig. 15.-Typical battery of wooden sulfur houses, each with capacity of two cars. Note sliding doors and counterweights.

daily output of the cutting shed are arranged in a row with a track and transfer car along the front to facilitate entrance of tray cars into each house. In large dry yards the houses are often built long enough or wide enough to hold two cars. 

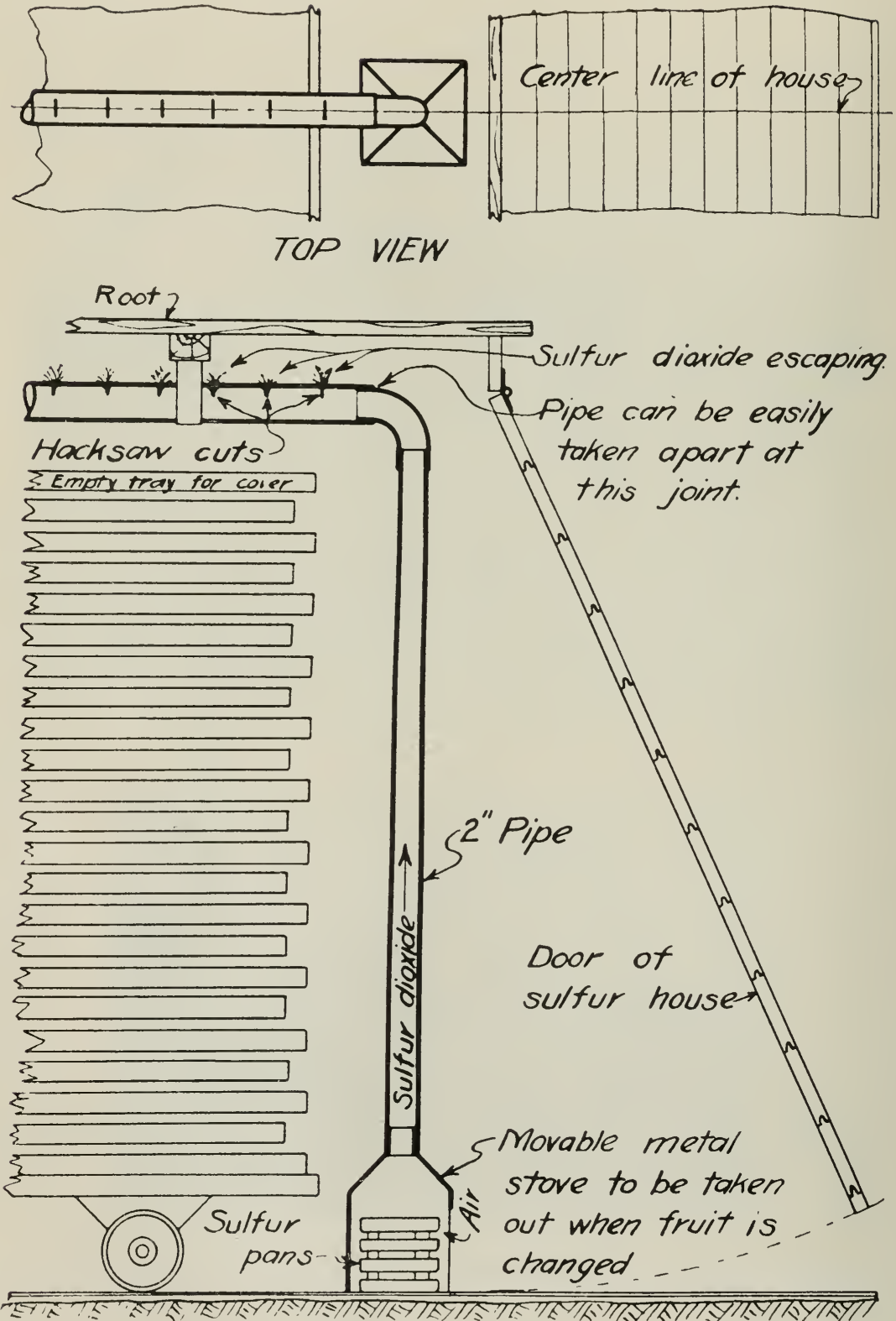

Fig. 16.-Metal sulfur-burning stove and distributing flue inside a tight sulfur house. (Courtesy of Dried Fruit Association of California.) 

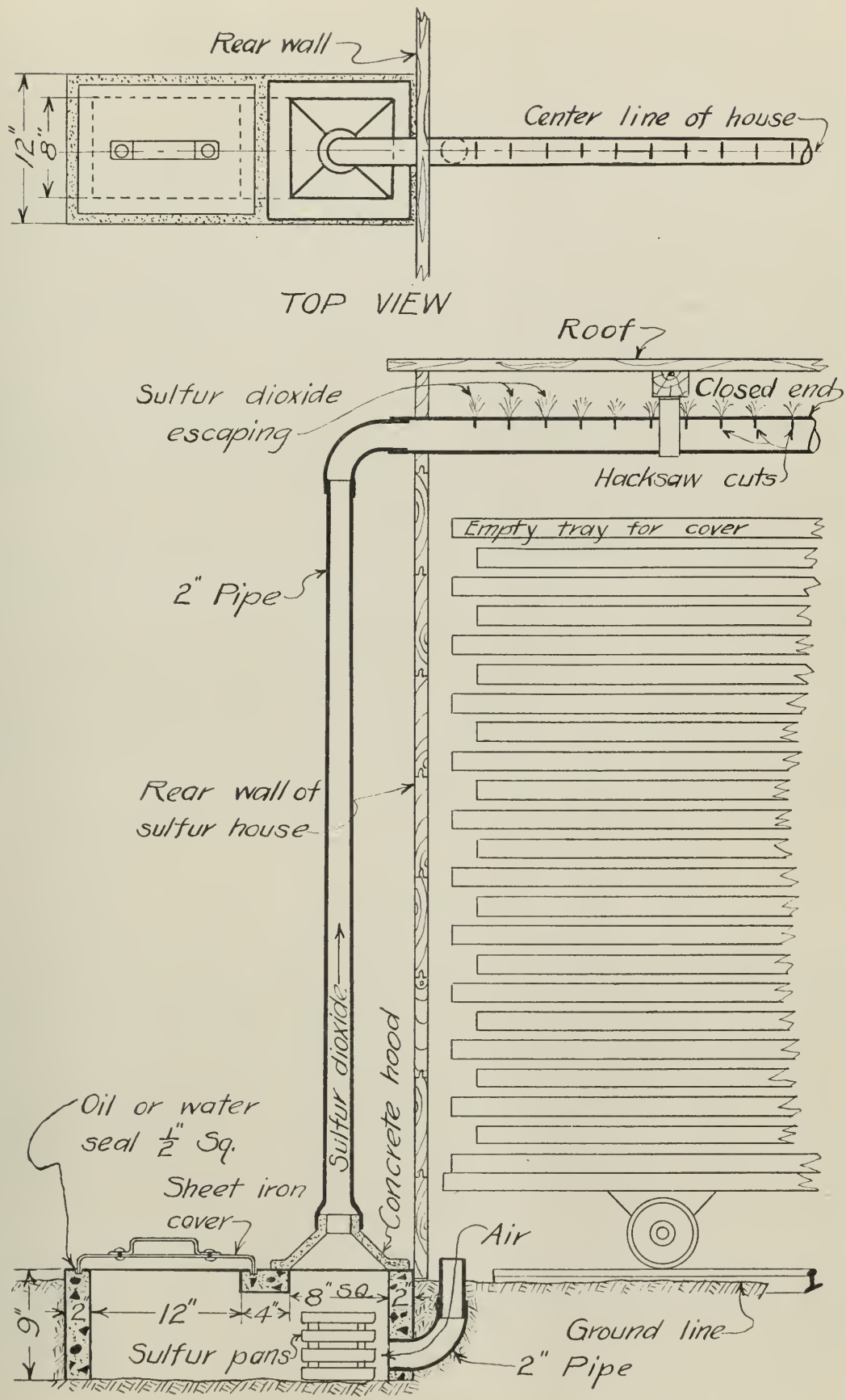

Fig. 16A-Concrete sulfur-burning stove and distributing flue outside a tight sulfur house. (Courtesy of Dried Fruit Association of California.) 
While the sulfur can be burned in a small pit in the ground, a better practice is to use a clean pan or bucket placed either on the floor inside the door or by means of a small opening for this purpose in the rear of the house. Such containers afford easy measurement of the sulfur and insure complete combustion without waste. Where the minimum necessary quantity of sulfur is used, it is essential that complete combustion of the sulfur and uniform distribution of the resulting gas throughout the house be secured. A sulfur stove, preferably of brick or concrete, with a distributing flue as illustrated in fig. 16, has been found to cause complete combustion and distribution of the sulfur fumes.

If such stoves are used, it is unnecessary to provide openings in the house for admission of additional air because, even if the sulfur house be hermetically sealed, it contains sufficient oxygen to burn at least two pounds of sulfur per ton of green fruit.

The number of sulfur houses required is dependent on the acreyield and the rate at which the fruit is picked and cut. With peaches and apricots, each sulfur house will care for from four to ten acres of orchard during the season, an average being one house to six acres. Each house can rarely be used for more than two trucks or from one to two tons of fruit daily. Since pears are normally sulfured 24 hours or longer, the number of sulfur houses required will be 2 or 3 times that required for peaches or apricots.

\section{SULFUR}

Any kind or brand of sulfur which is free from arsenic and will burn readily can be used in fruit drying. The kind most commonly used is known as sublimed flowers of sulfur. The light fluffy texture of this refined sulfur is such that it is readily ignited by a match or a bit of burning paper and burns steadily and completely without further attention. A cheaper form of sulfur is a ground or lump crude sulfur which is sufficiently pure for use on fruit. However, the physical condition of this sulfur is such as to require special sulfur burning stoves or pans to insure its combustion. These stoves or sets of superposed pans retain enough of the heat generated by the burning sulfur so that the sulfur burns continuously until all is consumed. While the use of the cheaper crude sulfur should result in a slight saving, most growers prefer the flowers of sulfur because it obviates the necessity of special stoves or pans and of frequent attention to the sulfur fires. All sulfur should be kept in a dry place to prevent 
absorption of moisture which would interfere with combustion. The admixture of not over 5 per cent of powdered sodium or potassium nitrate (saltpeter) (one pound to 20 pounds of sulfur) insures complete combustion even under adverse conditions.

\section{SWEAT BOXES AND BINS}

Various methods are in use for temporary storage of the dried fruit before delivery to the packing house. Some fruits, especially prunes, and to a considerable extent cut fruits are concentrated in large piles on a wooden or concrete floor for storage and equalization. The dried fruit may either be emptied into lug boxes in the dry-yard for transfer to the storage building or the trays of dried fruit can be stacked on cars and brought directly to the storage place for unloading. If large tonnages must be stored on a restricted floor area it becomes necessary to construct wooden bins, at least one wall of each being constructed of heavy removable boards to facilitate emptying. The construction of such bins is best learned by visiting a modern packing house. In calculating the capacity of dried fruit bins, the factors given in Table 8 will be found helpful.

\section{TABLE 8}

CAPACity Factors for Dried Fruit Bins

Fruit

Average pounds per cubic foot

Apricots. 54

Figs, white. 53

Figs, black. 55

Peaches. 49

Pears. 56

Prunes 59

The common method of transferring such fruits from the growers' bins to the packing house is in sacks, usually used grain sacks. A better method is to use lug or sweat boxes because sacks not only require sewing but also cause the fruit to accumulate dirt. Flat cut fruits such as peaches and apricots become more curled up when sacked. This results in a reduction of the percentages of the larger sizes when graded and for this reason box delivery is preferable.

Raisins and white figs are almost invariably collected in sweat boxes after drying in the vineyard or dry-yard. These boxes are strongly built with ends of $11 / 4^{\prime \prime}$ and sides and bottom of $7 / 8^{\prime \prime}$ pine, reinforced by corner posts. They are about $381 / 2^{\prime \prime} \times 263 / 4$ " by $73 / 4$ " deep and cost 
about $\$ 1.25$ each. The capacity varies from 100 to 200 pounds of dried fruit. They are used both to store and equalize the fruit after drying as well as containers in which to deliver to the packing house. Lug boxes are less satisfactory because of their smaller capacity but can be used, if available in sufficient numbers, to reduce the investment in equipment.

\section{PRACTICES OF SUN-DRYING FRUIT}

\section{PICKING METHODS}

Apricots and peaches should be picked from the tree when they have a uniform ripe yellow color, when they have begun to soften but are still reasonably firm and when they can be easily cut with a sharp knife and yet retain their shape. In order to obtain only well-ripened fruit it is necessary to pick over the orchard from two to four times in a season. The number of pickers required per acre of orchard averages one to four for peaches and one to two for apricots. The average adult will pick one thousand pounds of apricots or two thousand pounds of peaches a day. If knocked to the ground for gathering, these figures will be considerably increased but the fruit will be bruised and uneven in ripeness. The average cost of hand picking is three dollars and fifty cents per ton of peaches and seven dollars per ton of apricots.

Figs drop naturally to the ground when mature. The ground should be smoothed, to keep the figs cleaner and easier to gather. The trees may be lightly shaken but the fruit should never be knocked off. with poles. The fallen figs should be gathered frequently as exposure causes them to become sunburned, dirty and infested with insects. In practice, however, it is rarely possible to cover the orchard more than once or twice a week.

A simple and economical method is used with Mission figs in the Winters district. The fallen figs are picked directly into sacks, which, when one-third to one-half full, are tied and flattened out on the ground under the tree half way out from the trunk. The sacks are turned every two or three days until the figs are uniformly dried when several sacks are condensed for hauling to storage bins. Very uniform drying results in dry weather but the figs are apt to become excessively dirty and accumulate lint from the sack.

The entire cost of picking and drying by this method is about $\$ 17$ per dry ton and requires one picker to each two acres. 
White figs picked into boxes require about one picker to each eight acres, at the rate of one thousand pounds per picker daily. The cost of picking averages ten dollars per dry ton.

Pears are picked from the tree when hard ripe and still green in color and when the stem separates readily from the spur. It is necessary to pick over the orchard two or three times in order to secure pears of even maturity. Windfalls should be gathered frequently, preferably daily. In some orchards a layer of straw is spread under each tree to minimize bruising and keep the pears clean.

Grading and Ripening Pears.-When received at the preparation shed, pears should be graded before ripening in order to obtain evenness in both ripening and drying. Grading may be accomplished by hand or by special pear grading machines, the latter being more exact and economical for large plants. Wormy, sunburned, bruised or blemished fruit should be separated as it not only ripens faster but makes a second grade dried product. The sound pears are graded into from three to five sizes. In some localities the medium sizes are reserved for fresh shipment or canning. The various grades of each day's picking are stacked in separate boxes for ripening, which requires from five to ten days. During this time the pears are sorted two or three times to remove ripened or rotten pears. In the absence of sufficient boxes, pears may be ripened in shallow bins covered with a canvas or even between thick layers of straw under the shade of a tree or shed. Such methods, however, require more labor and result in greater loss from rotting. Pears are ready for cutting when they have acquired a uniform yellow color and full pear flavor, when slightly soft to thumb pressure yet still firm and not over-ripe or mushy.

Prunes are always picked from the ground, which should be smooth and free from vegetation to facilitate clean and rapid harvesting. If prunes remain on the tree after reaching maturity it becomes necessary to shake the trees or even knock the fruit off with poles in order that the crop may be gathered before the season becomes too late for sundrying.

The prune orchard is picked over on the average about four times, at intervals of a week or more. The final picking is preceded by a thorough shaking or knocking, in order to bring down all the remaining prunes. An average crop requires one picker for each five to seven acres. Adult pickers average nearly one ton a day, the rate of pay varying from four dollars to six dollars a ton. 
Grape pickers cut the stems with a sharp knife and spread the bunches directly on $2^{\prime} \times 3^{\prime}$ trays holding 18 to 22 pounds each. Before picking begins, trays are distributed between the rows and a ridge of soil thrown up against the south side of the east and west rows. The filled trays are placed against this ridge and are thus tilted toward the south in order to secure the maximum effect of the sunshine. Pickers are paid from two and one-half to five cents a tray according to the number of trays of grapes per unit of five hundred vines, the average being three and one-half cents a tray. This is equivalent to a cost of three dollars to three dollars and a half per ton of grapes. Generally the entire crop is removed at one picking.

Grapes which are dipped and sulfured before drying are picked into boxes and hauled to a dry-yard.

Boxes of fruit should not be allowed to remain in the orchard for more than one day after picking. They should be stacked in the shade and delivered to the preparation shed as promptly as possible in order that preparation and drying may begin while the fruit is in the freshest possible condition. This is especially important with fruit which has been bruised in falling to the ground.

\section{WASHING}

While not the general practice, washing apricots and peaches before cutting increases the quality of the dried product and therefore the price obtained, as has been demonstrated by comparative tests, because the fruit is cleaned and the surface left moist for the quick and uniform action of sulfur fumes. This is especially true of fruit gathered from the ground after being shaken from the tree.

The simplest method of washing consists in emptying the fruit from the picking boxes into slat bottom lug boxes, immersing in a tank of clean water, draining and using these boxes as service boxes to supply fruit to the cutters.

\section{CUTTING AND PITTING}

Apricots and peaches are cut by running a sharp knife around the line of the suture so that the knife blade returns to the point where the cut began. The two neatly cut halves are then separated, the pit picked out, and the two halves laid immediately on to a clean tray with the cut surface up. The fruit should not be cut part way around and then torn apart, as this leaves ragged unattractive edges. The pieces are placed close together to utilize the maximum capacity of the tray, but should not be crowded or overlapped as this causes 
the juice to spill out of the pit cavities when the trays are handled after sulfuring, resulting in a loss of weight and sticky fruit and trays. In order to keep the trays and fruit clean, uncut fruit should not be emptied on to the tray but should be removed from the lug box as it is eut and the pits thrown into a separate box or pan for collection and drying. Overripe fruit which will make "slabs" is preferably placed on separate trays so as to simplify culling the dried product. Rotten fruit should not be thrown back into the lug box or with the pits, but into a separate receptacle.

For apricots, an average of one cutter to each acre of orchard is required. Cutters are paid from seven to twenty-five cents a box, averaging thirteen cents, the rate being regulated to some extent by the size of the fruit but more by the local labor supply and demand. One person will cut from eight hundred to two thousand pounds daily, the average being about one thousand pounds. The cost of cutting ranges from $\$ 5$ to $\$ 8$, averaging $\$ 6$ a ton. Cutters should be paid at a rate per box which permits the grower to insist on proper eutting and still enables eutters to earn fair wages. Comparative tests have shown that improper cutting by underpaid cutters results in a greater loss in value of the dried product than the apparent saving from reduced cutting costs.

With peaches, one cutter for each 2 to 5 acres is required. Cutters are paid from six to ten cents a box and average two thousand pounds a day. The average cost of cutting peaches is $\$ 3.50$ a ton.

Pears are cut through the center from calyx to stem and the stem is pulled out. Worm holes should be trimmed out and some growers also trim out the calyx. The core can be removed from each half by a special steel loop pear corer. This gives the finest product but adds to the cost of preparation and reduces the yield. Cutters are paid from ten to twenty cents per box of 50 to 60 pounds net. The rate varies according to the locality, the size of the pears and the amount of trimming required. An experienced person can cut twenty boxes a day. The average rate in 1922 was fifteen cents a box, equivalent to about $\$ 5$ a ton.

\section{DIPPING}

Prunes should be dipped in a hot alkali solution as soon as is convenient after harvesting. The lye solution is made by adding 1 pound of lye to from 15 to 30 gallons of water, usually 1 pound to 20 gallons, which is equivalent to a concentration of 0.4 to 0.5 per cent lye. The temperature of the dip varies, with different operators, from lukewarm to boiling, but comparative experiments have shown the most efficient 
temperature to be $200^{\circ} \mathrm{F}$., which means that the dip should be maintained close to the boiling point. The time of immersion varies from a few seconds to half a minute but if the temperature and lye concentration are correct, from 5 to 15 seconds is ample. The strength of the solution must be maintained by periodic additions of lye to replace that lost mechanically and by partial neutralization of the fruit acid and at the end of each day's dipping the lye tank should be drained and a fresh solution made up for the next day.

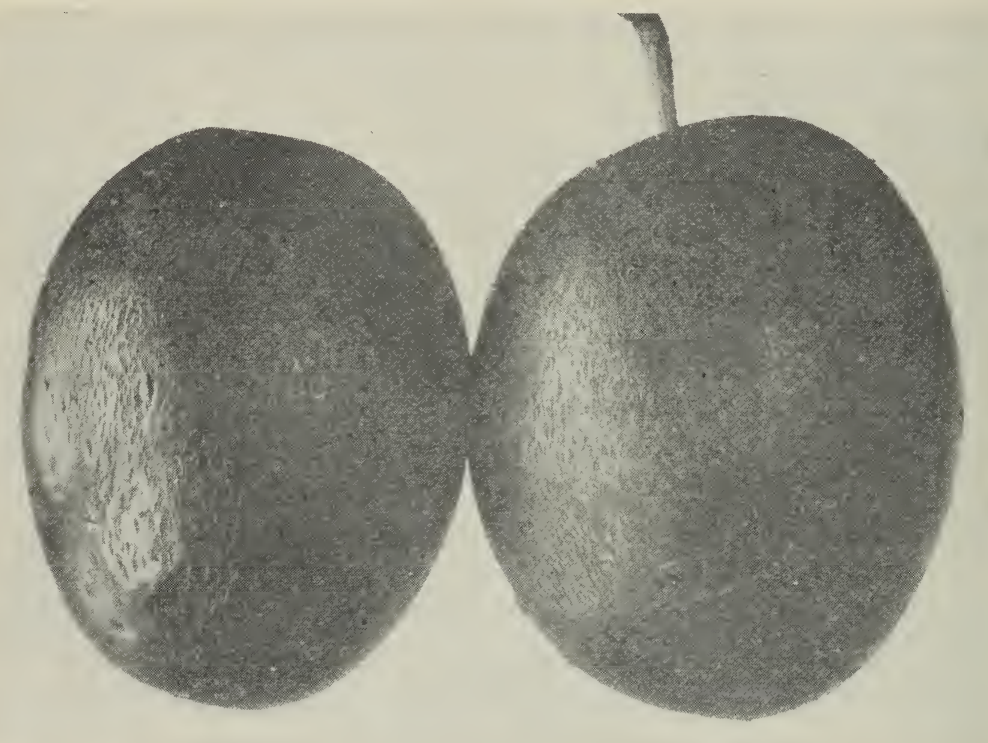

Fig. 17.-Effect of proper lye dipping on the skins of prunes.

Tough skinned varieties such as the Robe de Sergeant require a stronger solution and longer dip than more tender varieties, such as the Imperial. Frequent examination of the dipped prunes is necessary to regulate the strength of the dip and time of immersion in order that the skins of the majority of the prunes shall develop a number of minute cracks as shown in fig. 17. In general a short dip in a fairly strong lye solution close to the boiling point gives better results than a long dip in a weak or lukewarm lye. If the prunes are so tender as to become partially peeled in dipping, it is necessary to reduce the temperature or lye concentration or both. Some growers prefer to dip Imperials merely in warm water to which little or no lye is added.

If the dip can not be adjusted so as to check all the prunes, the use of a pricker board is advantageous because the skins of those prunes not checked by the dip are at least perforated. 
Rinsing after dipping is not practiced by all growers but is generally considered advisable. Rinsing may be done by immersing the prunes in a second tank through which fresh water is running but preferably by passing the prunes under water sprays.

The dipped prunes, either graded or ungraded, are discharged on to the trays and spread close together one layer deep only. The larger dipping outfits have a device for shaking the trays to minimize the amount of labor required in spreading. The filled trays are then stacked on trucks for transfer to the dry yard.

The number of men in a dipping crew varies from 3 on small handpower dippers to as high as 7 on the largest power dippers; averaging 5. The average daily capacity for a typical dipping crew was found to be about 7000 pounds per man. It is common practice for the erew to dip prunes during the forenoon and to spread the trayed prunes and do other dry-yard work in the afternoon. Recently, mechanical tray stackers installed in some orchards have eliminated two men from the dipping crew.

The average operating cost of dipping and spreading prunes on trays, presented in Table 9 , is based on exact measurements in over 20 dry-yards.

\section{TABLE 9}

Average Cost of Dipping and Traying Prunes

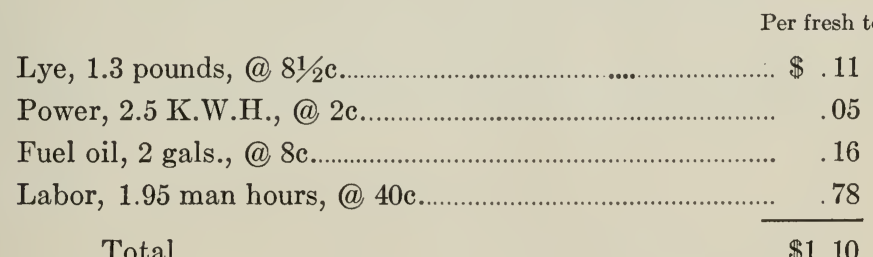

Total

$\$ 1.10$

Grapes.-Sultaninas and Sultanas are dipped before drying to produce the three commercial grades known as : Soda Dipped, Bleached and Oil Dipped. For the first two grades the grapes are dipped in much the same way as that just described for prunes. If the dip contains 1 pound of lye to every 10 to 20 gallons of water and is nearly boiling, satisfactory dipping is obtained in five seconds or less. Basket-type dippers must be used and the dipped grapes should be rinsed before traying. Because of the ease with which the skins of Sultanina grapes can be checked and of the danger of over-dipping, most growers prefer to use weaker brands of lye containing as much as 50 per cent sal soda. 
Soda-dipped raisins are placed directly in the dry-yard while bleached raisins are sulfured several hours after dipping and before drying.

Oil Dipped raisins are immersed for a few seconds in a cold solution of 30 pounds of bicarbonate of soda (baking soda) and 1 pound of lye in 100 gallons on which a thin film of olive oil is floated. The water may be heated to hasten the solution of soda if necessary. The soda dissolves the waxy bloom of the grapes and causes them to dry more rapidly. The thin film of olive oil with which the grapes become coated gives the finished raisins a glossy lighter brown color and a softer skin. For each green ton of grapes dipped, about 5 pounds of sodium bicarbonate and 1 quart of olive oil are consumed.

Figs.-The Adriatic is the only variety of fig which is dipped. A cold brine containing from 5 to 20 pounds of salt in 100 gallons of water is the most common dip, although some growers add an amount of lime equal to the salt. The function of this dip, which can be applied by immersion or preferably by sprays, is to cleanse the skin of the figs and leave them moist to facilitate the sulfuring which follows. Comparative experiments by the writers have shown that plain water is just as good and the expense for salt and making the brine is unnecessary.

\section{SULFURING}

Sulfuring methods vary considerably with variety of fruit, construction of sulfur houses, locality, temperature, etc. The figures in Table 10, represent what has been considered common practice.

\section{TABLE 10}

Average Amoun'ts of Sulfur and Times for Sulfuring Fruits

\begin{tabular}{|c|c|c|c|}
\hline Fruit & Hours exposed & $\begin{array}{l}\text { Pounds sulfur } \\
\text { per green ton }\end{array}$ & $\begin{array}{l}\text { Cost of sulfur } \\
\text { per green ton* }\end{array}$ \\
\hline Apricots.... & 4 & 7 & $\$ .28$ \\
\hline Peaches..... & 5 & 7 & .28 \\
\hline Pears................ & 36 & 12 & .48 \\
\hline Grapes (Seedless).. & 4 & 5 & .20 \\
\hline Figs (Adriatic)...... & 4 & 3 & .12 \\
\hline
\end{tabular}

* At 4 cents per pound.

The quantities of sulfur given in Table 10 are many times the quantity actually absorbed or required by the fruit. This is because most sulfur houses permit a steady escape of sulfur fumes and because 
many operators cause the fruit to absorb as much sulfur as possible, incorrectly believing that "if a drop is good, a bucketful is better."

Recent investigations by R. S. Hiltner, Technologist of the Dried Fruit Association of California, show that two pounds of sulfur per ton of peaches or apricots is ample to preserve the fruit provided this sulfur is completely burned and the fumes distributed in a tight house. For the benefit of the industry, growers should make their sulfur houses tight and restrict the amount of sulfur burned to the minimum required for color preservation.

In general it may be said that the best results are obtained by the use of the minimum amount of sulfur in a tight warm sulfur house and by allowing the fruit to remain in the house for 12 to 24 hours after the sulfur has ceased burning.

Apricots and Peaches.-In order that the surface of cut fruits will be moist for sulfuring, each tray of fruit should be sprinkled with water or a weak brine ( 1 pound of salt to each 4 gallons of water) as it is stacked. Salt aids in preventing the darkening of the fruit and reduces the amount of sulfur required. The trays should be alternately staggered about six inches at the ends to provide easy access of the fumes to the fruit. As soon as a stack is completed it should be immediately placed in the house for sulfuring. When apricots or peaches are sufficiently sulfured, the pit cavities will be nearly but not quite filled with juice, the skins will be loosened from the softened flesh and the pieces will appear uniformly transluscent, not "raw," either when cut transversely or viewed toward the sun.

Pears.-In Lake and Mendocino counties where the highest market grades of dried pears are produced, the fruit remains in the sulfur house from 24 to 72 hours, the sulfur being added in batches of 2 to 4 pounds at approximately 8 -hour intervals.

In other parts of the state as in Contra Costa County, pears are usually sulfured less than 24 hours with the result that the dried product, although of good flavor, is of a light brown color and brings a lower price.

The larger and greener the pears the longer the time of sulfuring. When ready for drying the flesh is softened throughout as if cooked and is white and transluscent while the skin is a light yellow. In order to prevent drying of the cut surface during sulfuring, pools or pans of water are used for maintaining a humid atmosphere within the house.

Grapes and Figs.-These fruits should be placed in the sulfur fumes while still moist from dipping and left until they acquire the uniform light yellow color desired. 


\section{DRYING}

Apricots and Peaches.-As soon as sulfuring is complete the trays should be transferred by truck to the dry-yard and spread in the sunshine, but never later than 3 or 4 P.M. The trays should be laid systematically in rows, preferably extending north and south and at right angles to the tracks. The north side of each tray should rest on the south edge of the preceding tray. This arrangement economizes space and by holding all but one edge of the tray off the ground helps in keeping the trays clean and in picking them up.

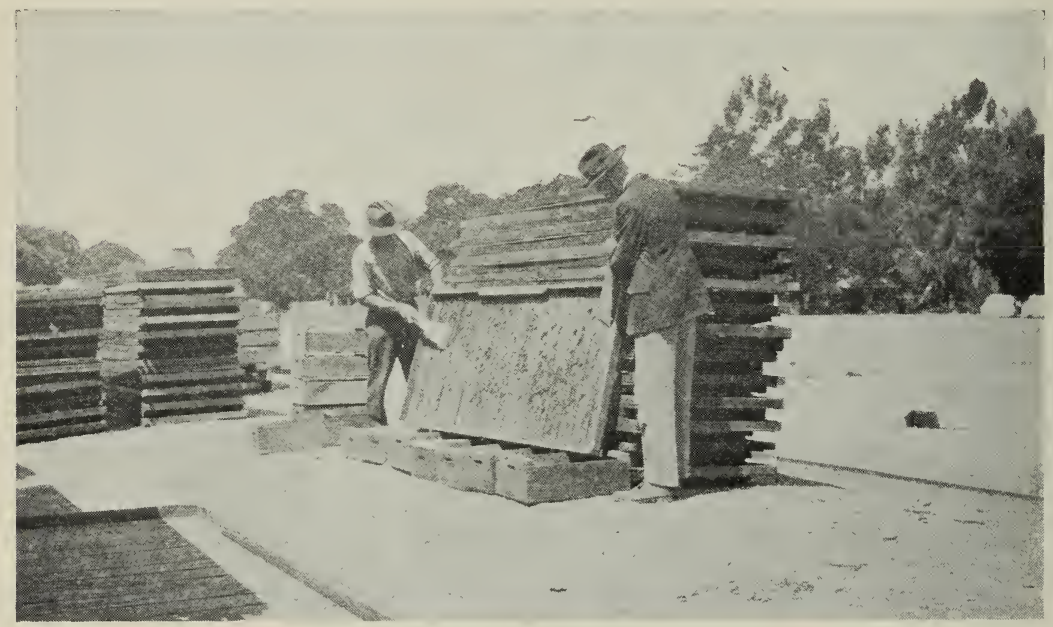

Fig. 18.-Scraping dried apricots into lug boxes. Note arrangement of trays for stack drying.

The fruit shculd remain exposed to direct sunshine until it is from a quarter to half dried and has acquired a uniform color. This will require from 1 to 5 days according to the temperature and air movement. The trays should then be stacked in a staggered pile with the open ends in the direction of the prevailing winds. After 2 to 6 days in the stack the fruit will be dry enough for storage. The total drying time varies greatly with locality and weather conditions but averages 7 days for apricots and 8 days for peaches.

Before the dried fruit from each tray is scraped into lug or sweat boxes (see fig. 18), discolored pieces, pits or other foreign matter should be picked out. This important culling can be done much more efficiently and economically at this point than at any later time. The dried fruit is then transferred from the dry-yard to the storage building. 
The ratio of the number of employees required for operating the cutting shed and dry-yard, exclusive of cutters, to the bearing acreage was found to average one man to each 8 acres of apricots or each 12 acres of peaches. The cost of this labor (at 40 cents an hour) was found to average $\$ 4.40$ for apricots and $\$ 4.60$ for peaches, per green ton.

Prunes.-Prunes are placed in the dry-yards in the way described for apricots and peaches but the trays are not stacked until the prunes are about three-fourths dried (see fig. 19). This requires from 5 to 10 days in dry weather. During this period large prunes, especially Imperials and Sugars, should be stirred by hand or a wooden rake. By turning them over (see fig. 20) and preventing their sticking to the tray, drying is made more rapid and uniform, and loss from mold or fermentation minimized.

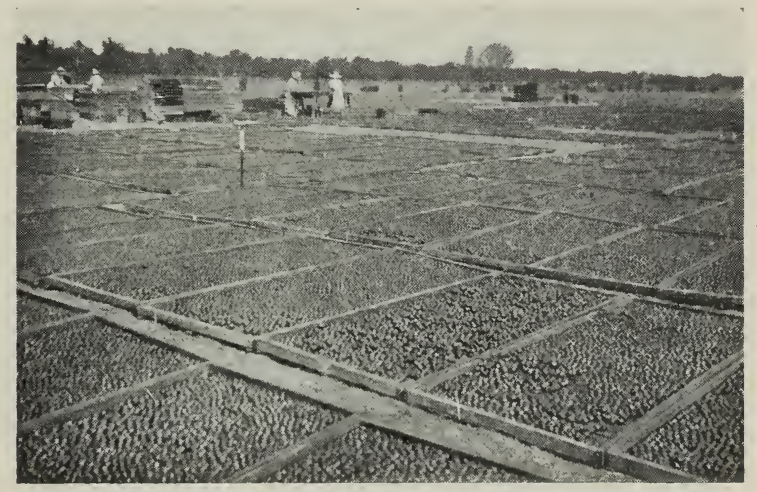

Fig. 19.-A large prune dry yard.

The trays are then stacked for completion of drying. This requires one week or longer according to weather conditions. Care must be taken not to stack prunes until they are at least three-fourths dry or they may spoil. It is rarely possible to properly dry prunes in less than 10 days and the average time in favorable weather is two weeks.

Prunes are sufficiently dry when the flesh, especially that around the pit, has changed to a thick or stiff syrupy condition and clings tight to the pit. When a handful is squeezed hard, the prunes should be sufficiently flexible to form a compact mass and yet not soft enough to stick together when the pressure is released. If some pits are cracked the kernels should be found dry and shrunken.

There are usually some prunes which do not dry satisfactorily and form what are popularly referred to as "bloaters," "frogs," "choco- 
lates," etc. These are the result either of inefficient dipping, or of immaturity, over-ripeness or partial decay of the prunes. All such defective prunes should be carefully culled out either during drying or before the trays are emptied as shown in fig. 21. Failure to do this will seriously lower the quality of the entire output.

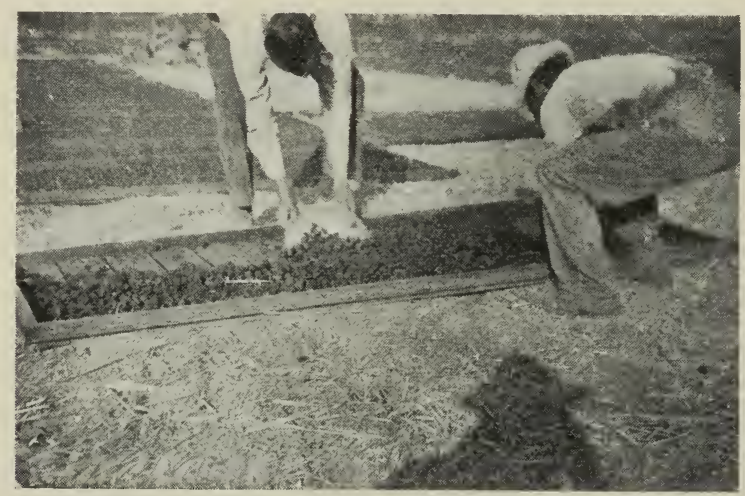

Fig. 20.-Turning prunes to facilitate drying.

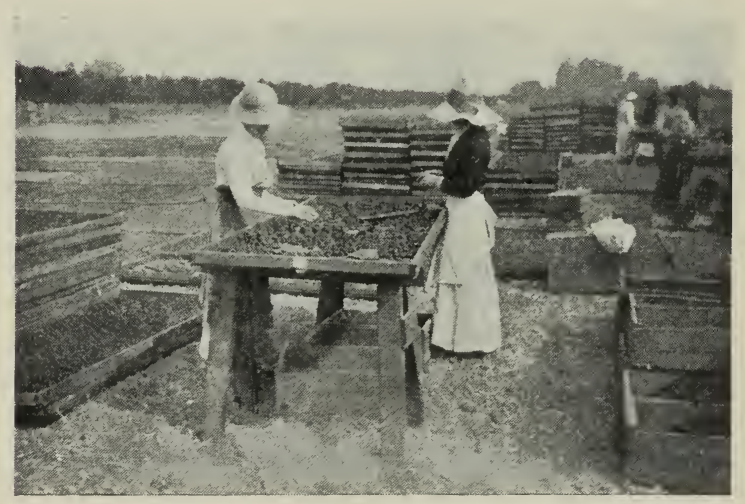

Fig. 21.--Sorting dried prunes.

The average number of dry-yard employees, exclusive of the dipping crew, was found to be one man to each 15 acres of bearing orchard. The average cost of all dry-yard labor, exclusive of dipping, was found to be about $\$ 2.40$ a green ton at a rate of 40 cents an hour.

In case of rain or heavy fog during the drying season, the trays must all be closely stacked and each stack covered with empty trays, canvas or a sheet of corrugated iron to prevent the prunes and trays from getting wet. If the prunes are already partially dried and the 
damp weather is of short duration, no serious damage will result. As soon as the air is comparatively dry again, the trays should be spread on the ground to complete the drying. If, as often occurs toward the latter part of the prune season, weather conditions do not permit of sun-drying, recourse must be had to dehydraters which at a temperature of $165^{\circ} \mathrm{F}$., which is safe, can economically complete the drying of the prunes in 24 hours or less without danger of spoiling. In fact, the economic advantages of modern dehydraters for prunes have caused many growers to use them exclusively in preference to the hazardous sun-drying.

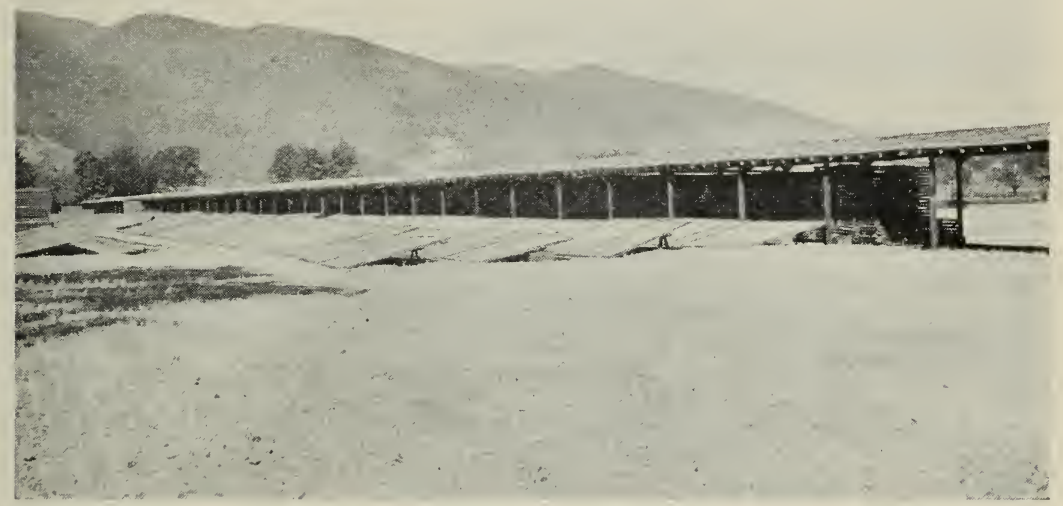

Fig. 22.-Drying pears in Lake County. (Note wooden horses for tilting trays toward south and open sheds for stack drying.)

Pears.-To preserve a light color, pears should be exposed to direct sunshine for only one-half to two days after sulfuring. In Lake County the north end of each tray is rested on wooden horses (about 1 to $1 \frac{1}{2}$ feet high) to give the pears the maximum sun exposure (see fig. 22). The trays are next stacked about 20 high, staggered, and with two 1-inch square cross-bars between each pair of trays to afford ample air circulation for drying. Each stack should be covered with a tray or other device to shade the top tray and shed rain. In Lake County permanent open-sided sheds are used to stack the trays under. Two to four weeks are usually required to complete drying, the trays being usually restacked two or more times to permit picking out culls and pears which have dried sufficiently. Rain damage is rare because of the high sulfur content of the pears and the protection afforded by stacking and sheds. 
Properly dried pears should be light colored and flat with little curling of the cut edges. They should not be mushy or puffy in the center but of a uniform texture similar to soft rubber.

Figs.-Because of variations in the moisture content of figs as usually picked, it is preferable to sort out and tray only those which are relatively soft and juicy and place all dried or nearly dried figs in storage. The length of time which trays of soft figs should be exposed to direct sunshine will depend on their moisture content and the temperature of the air. In very warm weather the trays of figs need not be exposed to direct sunshine but preferably allowed to remain stacked. In cooler weather it is generally necessary to expose the trays for two or three days before stacking, but care should be taken to prevent rapid or excessive drying, which results in a tough skin. Stirring the figs on the trays facilitates even drying.

The interior of a properly dried fig should have the consistency of a very thick fruit jam or butter and the skin should be soft and pliable, "like a kid glove." All figs which are split, bird pecked, moldy, sour or otherwise defective should be culled out before the figs are placed in sweat boxes for delivery to the packing house.

A simple and fairly satisfactory method of drying Mission figs in Yolo County is described on page 40.

Grapes.-There are two general methods of producing raisins from grapes :

1. Drying untreated grapes on trays between the rows in the vineyard.

2. Drying dipped grapes, with or without sulfur bleaching, on trays in a dry-yard.

Practically all Muscat raisins and the greater part of the Sultanina (seedless) raisins are dried in the vineyard, by the first or so-called "natural" method.

For this method, before the grapes are ripe for picking, a ridge is thrown up against the south side of every other east and west row of vines, with a plow or " $V$ " shaped drag. One man and team can cover about ten acres per day. This operation is referred to as " $V$ ' 'ing. At this time, the 2 ' $\times 3$ ' raisin trays are distributed in the vineyard. This is done at the approximate rate of 3000 trays a day for each two men and a team. The pickers cut the grapes from two adjacent rows simultaneously and spread them one bunch deep directly on the trays which are placed so that one end rests on the ridge which tilts the trays toward the south. Care should be taken to prevent the trays from being shaded by the vines, overhanging leaves being clipped off if necessary. 
After about four days the position of the ends of the trays is often reversed in order to secure more rapid and uniform drying. For the same reason, when the grapes on the upper surface of the bunches have become brown in color and partially shrivelled, the contents of the trays should be turned over. This is done by two men placing an empty tray on a filled one, lifting the two together off the ground and by a quick turn depositing the inverted bunches on the other tray. Two men can turn about 3000 trays a day.

When all the grapes have developed a uniform brown color and are from one-half to two-thirds dry, the trays are stacked in piles 20 or more trays high.

The use of paper trays is confined principally to the smaller, more rapidly drying seedless raisins. The ground between every other pair of rows should be smoothed by dragging, the papers spread on this ground and held down by a bunch of grapes until they are filled. When the raisins are nearly dry enough for stacking, the sides of the papers are turned in and the papers of raisins made into rolls which are then stacked like logs of wood.

When the grapes are sufficiently dry to be rolled between the fingers without exuding moistare, they are emptied from the trays into sweat boxes which have been previously distributed through the vineyard. Since each sweat box will hold about 150 pounds, 13 boxes for each ton of raisins will be required. Two men are able to box about 5 tons a day. The boxes may be collected at once, or if the weather permits, may be left in the vineyard. In either case, the raisins should be left in the boxes several weeks for thorough equalization of moisture before delivery to the packing house. After the trays are emptied they must be collected and removed from the vineyard.

The time required for the several stages in the drying varies considerably with the variety and size of the grapes, the locality, the time of year and the climate. The figures given in Table 11 will serve as an approximate guide.

TABLE 11

Approximate Average Time Required to Dry Raisins

\begin{tabular}{|c|c|c|}
\hline & Sultanina & Muscat \\
\hline & \multirow{5}{*}{$\begin{array}{c}\text { Days } \\
7-8 \\
3-4 \\
7 \\
21\end{array}$} & \multirow{5}{*}{$\begin{array}{c}\text { Days } \\
10-12 \\
5-7 \\
7 \\
21\end{array}$} \\
\hline Turn after..... & & \\
\hline Stack after... & & \\
\hline Box after........ & & \\
\hline Deliver after & & \\
\hline
\end{tabular}


The production of dried currants from the Black Corinth, a very small black seedless grape, is the same as for seedless raisins except that in hot climates like the San Joaquin Valley the best quality is obtained by drying in the stack without preliminary exposure to direct sunshine.

The drying of dipped or bleached grapes in a dry-yard is similar to that of untreated grapes in the vineyard. In drying dipped, but unsulfured grapes, the bunches should be turned often enough to prevent molding, and with the same object, the trays should not be stacked until the raisins are too dry to mold. To obtain a uniform light amber color in sulfur bleached raisins, they should be exposed to direct sunshine as short a time as possible- one to four days, according to the temperature. After the grapes have acquired a uniform amber color and are partially shriveled, drying is preferably completed in the stack.

During seasons of early fall rains, considerable delay and extra labor is unavoidable in completing the sun-drying of raisins. Occasional light showers will do no damage if the trays are stacked and covered with an empty tray and when the weather clears, the trays are spread out again. Paper trays should be rolled and placed under the vines for protection until they can be spread out again to complete drying. Raisins which have been wet by rains can be prevented from molding by covering each stack of trays with a sulfuring hood of suitable size and shape similar to that shown in fig. 12, and burning about half a pound of sulfur to each 25 trays as described in Circular 211 of this station. If several hoods are used, the operation becomes rapid and continuous.

If a long period of rainy weather occurs, recourse must be had to a dehydrater. While dehydration has not been found economical in the production of the desired quality of Muscat raisins starting from the freshly picked grapes, the use of dehydration at the safe temperature of $160^{\circ} \mathrm{F}$., is valuable in rapidly completing the drying of partially sun-dried raisins during rainy weather. Growers who have "rain damage" dehydraters for emergency use have been able to save the cost of such dehydraters in a few years because of the greater yield and quality of raisins obtained by delaying the picking of the grapes until they have reached full maturity. Even though not needed every year, an inexpensive dehydrater is valuable as insurance against damage or loss to raisins.

In recent years, dehydraters have come into considerable use for drying soda dipped or sulfur bleached seedless raisins in the Sacramento Valley. If weather permits, the trays are usually spread in 
the dry-yard for one day to give the raisins a more uniform color, after which drying can be quickly, and economically completed in the dehydrater. For safety, the temperature should not exceed $160^{\circ} \mathrm{F}$., with dipped, or $150^{\circ} \mathrm{F}$., with bleached raisins.

\section{SUMMARY OF COST OF DRYING}

During the survey of dry-yards, on which the information presented in this bulletin is based, much valuable information on the costs of picking and drying fruits was obtained. Although not a primary function of this bulletin, it was thought desirable to summarize the cost data because of their value as a guide in estimating costs of producing dried fruits.

As few growers keep itemized accounts of their costs of operation, it was necessary to calculate average costs from a comparatively small number of reports. However, all the data used in compiling the following tabulations were obtained from exact records kept by experienced growers and may be considered reliable.

Some of the more important factors which cause variations in costs of producing dried fruits may be briefly enumerated as follows:

1. Variety of fruit.

2. Size of fruit.

3. Acreage yield.

4. Methods of picking, cutting and drying.

5. Adequacy, efficiency and arrangement of dry-yard and accessory equipment.

6. Rapidity and uniformity of drying as affected by climatic and weather conditions.

7. Rates for labor and supplies.

8. Efficiency of labor.

9. Drying ratio of fruit.

Because of these variables, some of which are beyond the control of the grower, the figures given in the following tables can be considered only as approximate averages.

Growers will find it very useful to keep a simple account book in which to record daily the quantity of green and dried fruit handled, itemized costs of labor and supplies, etc. This information is invaluable in considering economic improvements in methods or equipment. 


\section{OPERATING COSTS}

The costs given in the following tables include, in addition to the labor cost of picking, all items of labor and supplies required from the time the fruit is delivered to the dry-yard until the dried product is in temporary storage awaiting shipment to a packing house. There are always additional charges for hauling the fresh fruit to the dry-yard and for hauling the dried product to a packing house which are not included here because of insufficient data. There are also additional seasonal charges for labor in washing, repairing and storing trays and boxes; in care of dry-yard, tracks and other equipment at the beginning and end of the season, etc., which must be prorated among the total tons of fruit dried during the season. Such items are much less than the direct costs of handling the fruit but are nevertheless appreciable and should not be lost sight of in compiling the total cost of production.

\section{TABLE 12}

Average Cost of Picking and Drying Apricots (Santa Clara County, Six GrowFrs, 1921)

\begin{tabular}{|c|c|c|}
\hline & Per green ton & Per dry ton* \\
\hline Picking, @371/2c per hour....... & \multirow{4}{*}{$\begin{array}{r}\$ 6.16 \\
5.45 \\
4.38 \\
.35\end{array}$} & \multirow{4}{*}{$\begin{array}{r}\$ 30.80 \\
27.25 \\
21.90 \\
1.75\end{array}$} \\
\hline Cutting,@11c per 40-lb. box.......... & & \\
\hline All otherlabor, @371/2c per hour.. & & \\
\hline Sulfur, 7 lbs. @ 5c............................. & & \\
\hline Totals.... & $\$ 16.34$ & $\$ 81.70$ \\
\hline
\end{tabular}

* Average gross shrinkage $5: 1$.

TABLE 13

Average Cost of Picking and Drying Peaches (San Joaquin Valley, FOUR GROWERS, 1921)

\begin{tabular}{|c|c|c|}
\hline & Per green ton & Per dry ton* \\
\hline Picking, @ 421/2c per hour................... & $\$ 3.02$ & $\$ 15.10$ \\
\hline Cutting, @ 8c per 50-lb. box.............................. & 3.30 & 16.50 \\
\hline All other labor, @ 45c per hour...................... & 4.58 & 22.90 \\
\hline Sulfur, 81/2 lbs. @ 5c................ & .42 & 2.10 \\
\hline Total... & $\$ 11.32$ & $\$ 56.60$ \\
\hline
\end{tabular}

* Average gross shrinkage $5: 1$. 
Pears.-Table 14 summarizes data obtained in 1921 at several large custom dry-yards in Mendocino and Lake counties on the costs of ripening, cutting and drying pears, with an average shrinkage of $4.3: 1$. The cost does not include picking.

TABLE 14

Average Cost of Drying Pears

\begin{tabular}{|c|c|c|}
\hline & Per green ton & Per dry ton \\
\hline Cutting, @ 15c per box......................... & $\$ 5.10$ & $\$ 21.93$ \\
\hline Labor (all other), @ 40c per hour.. & 10.60 & 45.58 \\
\hline Sulfur,@ $@$ c a pound.......................... & .48 & 2.06 \\
\hline Total... & $\$ 16.18$ & $\$ 69.57$ \\
\hline
\end{tabular}

Prunes.-The figures on the cost of picking and drying prunes, presented in Table 15, were obtained in 11 dry-yards ranging in size from small to large and equally distributed between the Santa Clara and Sacramento valleys. The labor and supplies required for dipping and drying ranged from $\$ 1.60$ to $\$ 6.15$, averaging $\$ 4.21$ a green ton.

TABLE 15

Average Cost of Picking and Drying Prunes (1921)

\begin{tabular}{|c|c|c|}
\hline & Per green ton & Per dry ton* \\
\hline Picking (by contract)............... & \multirow{4}{*}{$\begin{array}{r}\$ 4.90 \\
.78 \\
.32 \\
3.11\end{array}$} & \multirow{4}{*}{$\begin{array}{r}\$ 11.03 \\
1.76 \\
.72 \\
7.00\end{array}$} \\
\hline 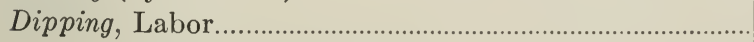 & & \\
\hline Supplies (see Table 9) & & \\
\hline Drying, Labor @ 371/2c per hour............................... & & \\
\hline Total.. & $\$ 9.11$ & $\$ 20.51$ \\
\hline
\end{tabular}

* Average shrinkage $2 \frac{1}{3}: 1$.

Figs.-Data obtained from three experienced Calimyrna fig growers in the San Joaquin Valley in 1921 showed costs of $\$ 20$ to $\$ 22$ per dry ton for picking and drying, of which $\$ 8$ to $\$ 10$ per ton was paid for picking at the rate of 20 cents for each 40- to 50-pound box.

Detailed costs of drying a 120-ton crop of Adriatic figs is presented in Table 16.

Limited data on the cost of picking and drying Mission figs in the orchard by the sack method varied from $\$ 16$ to $\$ 20$ per dry ton. 


\section{TABLE 16}

Cost of Picking and Drying Adriatic Figs

Kearney Park Vineyard-Fresno, 1921.

Per dry ton

Picking,@14c per 46-lb.box

$\$ 8.16$

Labor, dipping and drying, @ 40c per hour.

13.07

Salt, 19 lbs.@3/4c

.14

Sulfur, 13 lbs.@4c

Power, 14.5 K.W.H. @ 21/2c. (For operation of dipper)

.36

Total.

$\$ 22.25$

Raisins.-Itemized costs of all the operations involved in raisin drying were not obtained but records obtained in 1919 and 1920 from several efficiently operated raisin vineyards in the San Joaquin Valley gave costs closely approximating $\$ 9$ per green ton, which, on an average drying ratio of $3 \frac{1}{2}: 1$, is equivalent to $\$ 31.50$ per ton of finished raisins. This cost includes all labor and teams used in preparing the ground, distributing trays and boxes to and from the vineyard, picking, turning, stacking and boxing, but not hauling to the packing house. Since that time the cost of picking and traying has been reduced about onethird which makes present costs about $\$ 7$ per green ton or $\$ 24$ per dry ton. An additional charge of 1 cent per tray and 5 cents per sweat box should be allowed for annual repairs.

\section{FIXED CHARGES}

Any consideration of the total cost of drying fruits would be incomplete without reference to the annual fixed charges on the equipment required. Many growers neglect to include this important item in calculating costs of production. The investment in each of the following items of equipment should be recorded.

1. Area of land reserved for dry-yard.

2. Buildings used for cutting, dipping, sulfuring and storing fruits.

3. Lug boxes, trays and sweat boxes.

4. Cars and tracks.

5. Accessory equipment such as dippers, graders, tables, etc.

In general, there are five charges properly made against the investment represented by this equipment. These are interest, depreciation, upkeep, insurance and taxes. Interest is usually calculated at a rate of $5 \%$ on the current investment. Depreciation and upkeep 
together will vary from $5 \%$ to $15 \%$ according to the nature of the equipment, its use and manner of construction. For instance, dry-yard land would presumably suffer no depreciation, while trays and boxes often require an annual depreciation charge of $10 \%$ or more. Insurance on combustible buildings and equipment is frequently carried at rates averaging $2 \%$ to $3 \%$ of their value. Taxes are variable but will rarely exceed $3 \%$ on an assessed valuation equal to $50 \%$ of the investment ( $1 \frac{1}{2} \%$ on the market value).

Taking into consideration the entire equipment, including land, an annual fixed charge of about $15 \%$ to $20 \%$ is usually sufficient to cover all the above-mentioned items. However, each grower should carefully determine his own proper allowance for fixed charges. This should then be divided by the number of tons of fruit dried during the year and added to the previously recorded direct cost of labor and materials used in drying the fruit.

Fixed charges per ton vary rather widely, the chief factors of difference being : first, the amount and nature of equipment used and, second, the tonnage dried in any given year. Sufficient exact data on fixed charges from which to compile reliable averages was not obtained. However, the following tables are presented as guides in tabulating equipment costs and prorating fixed charges thereon.

Apricots.-The investment in apricot drying equipment given in Table 17, has been calculated from data furnished by W. R. Kingston of Ventura County. The figures are for equipment capable of drying 100 tons (fresh weight) of apricots per season. Assuming an annual fixed charge of $15 \%$ on a total investment of $\$ 2253$, there would be a fixed charge of $\$ 3.38$ per fresh ton, which on a drying ratio of $5: 1$ would equal $\$ 16.90$ per dry ton. No charge is made for dry-yard land, it being assumed that before the drying season some annual crop of sufficient value can be harvested from the land to at least cover the interest on the value of the land in addition to the cost of production.

Similar data furnished by Martin J. Madison of the California Prune and Apricot Growers' Association, for a plant capable of drying 300 fresh tons of apricots per season, is summarized in Table 18.

Prunes.-Data obtained from four prune growers in Santa Clara County with an annual production of $70,165,190$ and 1500 fresh tons, respectively, gave fixed charges of $\$ 3.64, \$ 2.60, \$ 4.24$ and $\$ 3.23$ per fresh ton, respectively. With an average drying ratio of $21 / 4: 1$, the above figures represent an average fixed charge of $\$ 7.70$ per ton of dried prunes. 


\section{TABLE 17}

\section{InVEstment in APRICot DRying EQUipment}

(After W. R. Kingston, Ventura County)

Equipment for 100 fresh tons per season.

Cost per fresh ton

$300-50$ pound picking boxes at $36 \mathrm{c}$ $\$ 1.08$

$1200-3^{\prime} \times 8^{\prime}$ trays at $\$ 1.05$ 12.60

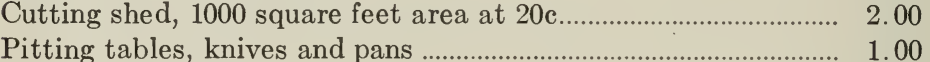

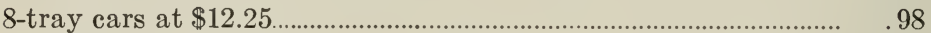

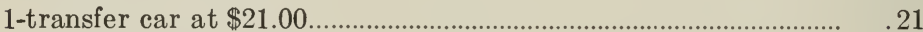

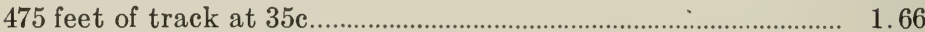

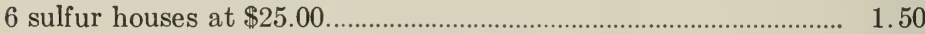

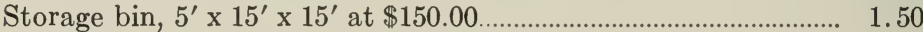

Total investment per fresh ton $\$ 22.53$

Fixed charge per fresh ton at $15 \%$......................................... 3.38

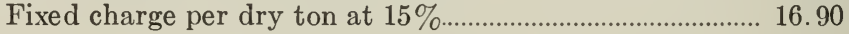

TABLE 18

Investment in Apricot Drying Equipment

(After M. J. Madison, San Jose)

Equipment for 300 fresh tons per season.

Cost per fresh ton

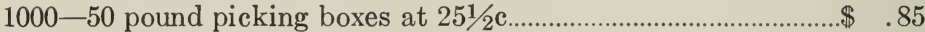

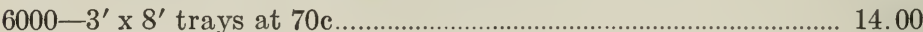

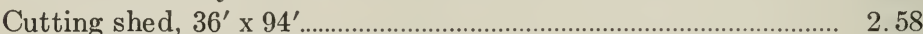

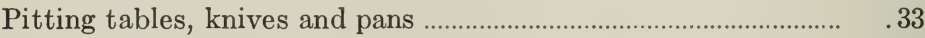

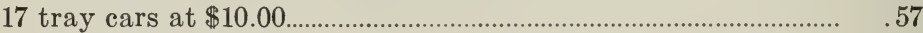

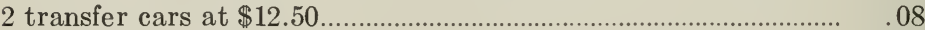

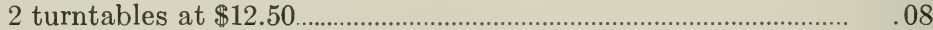

1500 feet of track with rails, ties and spikes................................... $\quad .78$

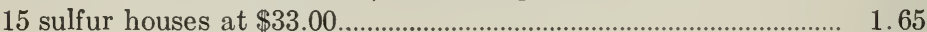

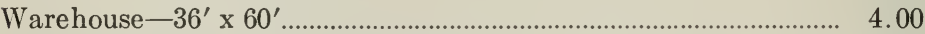

7 hand trucks and 1 platform scale .............................................. $\quad .77$

Total investment per fresh ton ...............................................\$25.69

Fixed charge per fresh ton at $15 \%$.......................................... 3.85

Fixed charge per dry ton at $15 \%$.......................................... 19.25 


\section{BULLETINS}

No.

253. Irrigation and Soil Conditions in the Sierra Nevada Foothills, California.

261. Melaxuma of the Walnut, "Juglans regia."

262. Citrus Diseases of Florida and Cuba Compared with Those of California.

263. Size Grades for Ripe Olives.

268. Growing and Grafting Olive Seedlings.

273. Preliminary Report on Kearney Vineyard Experimental Drain.

275. The Cultivation of Belladonna in California.

276. The Pomegranate.

277. Sudan Grass

278. Grain Sorghums.

279. Irrigation of Rice in California

280. Irrigation of Alfalfa in the Sacramento Valley.

283. The Olive Insects of California.

285. The Milk Goat in California.

286. Commercial Fertilizers.

294. Bean Culture in California.

304. A Study of the Effects of Freezes on Citrus in California.

310. Plum Pollination.

312. Mariout Barley.

313. Pruning Young Deciduous Fruit Trees.

319. Caprifigs and Caprification.

324. Storage of Perishable Fruit at Freezing Temperatures.

325. Rice Irrigation Measurements and Experiments in Sacramento Valley, 1914-1919.

328. Prune Growing in California.

331. Phylloxera-Resistant Stocks.

334. Preliminary Volume Tables for Second. Growth Redwood.

335. Cocoanut Meal as a Feed for Dairy Cows and Other Livestock.

339. The Relative Cost of Making Logs from Small and Large Timber.

340. Control of the Pocket Gopher in California.

343. Cheese Pests and Their Control.

344. Cold Storage as an Aid to the Marketing of Plums.

346. Almond Pollination.

347. The Control of Red Spiders in Decidu. ous Orchards.

348. Pruning Young Olive Trees.

349. A Study of Sidedraft and Tractor Hitches.

350. Agriculture in Cut-over Redwood Lands.
No.

352. Further Experiments in Plum Pollination.

353. Bovine Infectious Abortion.

354. Results of Rice Experiments in 1922.

357. A Self-mixing Dusting Machine for Applying Dry Insecticides and Fungicides.

358. Black. Measles, Water Berries, and Related Vine Troubles.

359. Fruit Beverage Investigations.

361. Preliminary Yield Tables for Second Growth Redwood.

362. Dust and the Tractor Engine.

363. The Pruning of Citrus Trees in California.

364. Fungicidal Dusts for the Control of Bunt.

366. Turkish Tobacco Culture, Curing and Marketing.

367. Methods of Harvesting and Irrigation in Relation to Mouldy Walnuts.

368. Bacterial Decomposition of Olives dur. ing Pickling.

369. Comparison of Woods for Butter Boxes.

370. Browning of Yellow Newtown Apples.

371. The Relative Cost of Yarding Small and Large Timber.

372. The Cost of Producing Market Milk and Butterfat on 246 California Dairies.

374. A Survey of Orchard Practices in the Citrus Industry of Southern California.

375. Results of Rice Experiments at Cortena, 1923.

376. Sun-Drying and Dehydration of Walnuts.

377. The Cold Storage of Pears.

379. Walnut Culture in California.

380. Growth of Eucalyptus in California Plantations.

381. Growing and Handling Asparagus Crowns.

382. Pumping for Drainage in the San Joaquin Valley, California.

383. Monilia Blossom Blight (Brown Rot) of Apricot.

384. A Study of the Relative Values of Certain Succulent Feeds and Alfalfa Meal as Sourses of Vitamin A for Poultry.

385. Pollination of the Sweet Cherry.

386. Pruning Bearing Deciduous Fruit Trees.

387. Fig Smut.

\section{CIRCULARS}

No.

87. Alfalfa.

113. Correspondence Courses in Agriculture.

117. The Selection and Cost of a Small Pumping Plant.

127. House Fumigation.

129. The Control of Citrus Insects.

136. Melilotus indica as a Green-Manure Crop for California.

144. Oidium or Powdery Mildew of the Vine.

151. Feeding and Management of Hogs.

152. Some Observations on the Bulk Hand. ling of Grain in California.

154. Irrigation Practice in Growing Small Fruit in California.
No.

155. Bovine Tuberculosis.

157. Control of the Pear Scab.

160. Lettuce Growing in California.

161. Potatoes in California.

164. Small Fruit Culture in California.

165. Fundamentals of Sugar Beet Culture under California Conditions.

166. The County Farm Bureau.

167. Feeding Stuffs of Minor Importance.

170. Fertilizing California Soils for the 1918 Crop.

173. The Construction of the Wood-Hoop Silo.

178. The Packing of Apples in California. 
No.

179. Factors of Importance in Producing Milk of Low Bacterial Count.

184. A Flock of Sheep on the Farm.

190. Agriculture Clubs in California.

199. Onion Growing in California.

202. County Organizations for Rural Fire Control.

203. Peat as a Manure Substitute.

208. Summary of the Annual Reports of the Farm Advisors of California.

209. The Function of the Farm Bureau.

210. Suggestions to the Settler in California.

212. Salvaging Rain-Damaged Prunes.

214. Seed Treatment for the Prevention of Cereal Smuts.

215. Feeding Dairy Cows in California.

217. Methods for Marketing Vegetables in California.

220. Unfermented Fruit Juices.

228. Vineyard Irrigation in Arid Climates.

231. The Home Vineyard.

232. Harvesting and Handling California Cherries for Eastern Shipment.

233. Artificial Incubation.

234. Winter Injury to Young Walnut Trees during 1921-22.

235. Soil Analysis and Soil and Plant Interrelations.

236. The Common Hawks and Owls of California from the Standpoint of the Rancher.

237. Directions for the Tanning and Dressof Furs.

238. The Apricot in California.

239. Harvesting and Handling Apricots and Plums for Eastern Shipment.

240. Harvesting and Handling Pears for Eastern Shipment.

241. Harvesting and Handling Peaches for Eastern Shipment.

243. Marmalade Juice and Jelly Juice from Citrus Fruits.

244. Central Wire Bracing for Fruit Trees.

245. Vine Pruning Systems.

247. Colonization and Rural Development.

248. Some Common Errors in Vine Pruning and Their Remedies.

24.9. Replacing Missing Vines.

250. Measurement of Irrigation Water on the Farm.
No.

251. Recommendations Concerning the Oommon Diseases and Parasites of Poultry in California.

252. Supports for Vines.

253. Vineyard Plans.

254. The Use of Artificial Light to Increase Winter Egg Production.

255. Leguminous Plants as Organic Fertilizer in California Agriculture.

256. The Control of Wild Morning Glory.

257. The Small-Seeded Horse Bean.

258. Thinning Deciduous Fruits.

259. Pear By-products.

260. A Selected List of References Relating to Irrigation in California.

261. Sewing Grain Sacks.

262. Cabbage Growing in California.

263. Tomato Production in California.

264. Preliminary Essentials to Bovine Tuberculosis Control.

265. Plant Disease and Pest Control.

266. Analyzing the Citrus Orchard by Means of Simple Tree Records.

267. The Tendency of Tractors to Rise in Front: Causes and Remedies.

268. Inexpensive Lavor-saving Poultry Appliances.

269. An Orchard Brush Burner.

270. A Farm Septic Tank.

271. Brooding Chicks Artificially.

272. California Farm Tenancy and Methods of Leasing.

273. Saving the Gophered Citrus Tree.

275. Marketable California Decorative Greens.

276. Home Canning.

277. Head, Cane, and Cordon Pruning of Vines.

278. Olive Pickling in Mediterranean Countries.

279. The Preparation and Refining of Olive Oil in Southern Europe.

281. The Results of a Survey to Determine the Cost of Producing Beef in California.

282. Prevention of Insect Attack on Stored Grain.

283. Fertilizing Citrus Trees in California.

284. The Almond in California.

The publications listed above may be had by addressing

College of Agriculture, University of California, Berkeley, California. 